\title{
A Framework to Predict the Load-Settlement Behavior of Shallow Foundations in a Range of Soils from Silty Clays to Sands using CPT Records
}

Hossein MolaAbasi

Gonbad Kavous University

Aghileh Khajeh

University of Guilan

REZA JAMSHIDI CHENARI ( $\nabla$ jamshidi_reza@yahoo.com )

University of Guilan https://orcid.org/0000-0002-7950-322X

Meghdad Payan

University of Guilan

\section{Research Article}

Keywords: Load-settlement curve, CPT, Ultimate bearing capacity, Volterra series, Sensitivity analysis.

Posted Date: July 12th, 2021

DOl: https://doi.org/10.21203/rs.3.rs-697719/v1

License: (c) This work is licensed under a Creative Commons Attribution 4.0 International License.

Read Full License

Version of Record: A version of this preprint was published at Soft Computing on October 31st, 2021. See the published version at https://doi.org/10.1007/s00500-021-06485-8. 

Behavior of Shallow Foundations in a Range of Soils

\section{from Silty Clays to Sands using CPT Records}

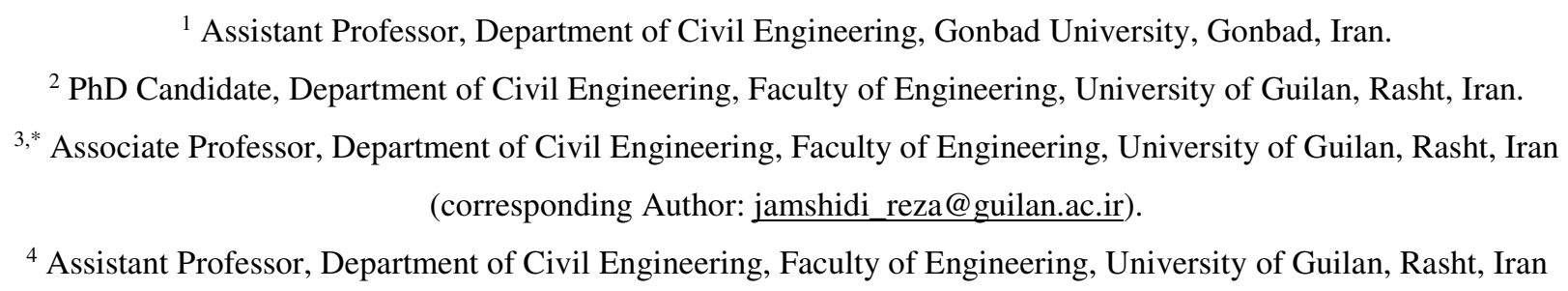

${ }^{4}$ Assistant Professor, Department of Civil Engineering, Faculty of Engineering, University of Guilan, Rasht, Iran

\section{Abstract}

12 Using a set of cone penetration test $(C P T)$ records, the current paper develops a general

13 framework based on regression analyses to model the load-settlement $(q-s)$ behavior of shallow

14 foundations resting on a variety of soils ranging from silty clays to sands. A three-parameter

15 hyperbolic function is employed to rigorously examine the obtained $q-s$ curves, and to determine

16 the model parameters. Also, the results of some CPT soundings, including the corrected cone tip

17 resistance $\left(q_{t}\right)$ and the skin friction $\left(R_{f}\right)$, are adopted to predict the results of plate load tests

18 (PLT). The findings corroborate the high accuracy of the proposed model, the reasonable

19 performance of the hyperbolic function and the use of the Volterra series to predict the $q-s$

20 curves. Moreover, the obtained curves from the newly developed model are compared to those

21 from other methods in the literature which cross-confirms the efficacy of the current model. A

22 sensitivity analysis is also conducted and the exclusive effects of all the contributing parameters

23 are assessed among which $R_{f}$ is shown to be the most influential. Ultimately, simple solutions are 
24 adopted to determine various key geotechnical parameters, like the ultimate bearing capacity

$25\left(q_{u l t}\right)$, the allowable bearing capacity $\left(q_{a}\right)$ and the modulus of subgrade reaction $\left(k_{s}\right)$.

26 Keywords: Load-settlement curve; CPT; Ultimate bearing capacity; Volterra series; Sensitivity

27 analysis.

\section{Nomenclature}

\begin{tabular}{|c|c|}
\hline Net area ratio of cone tip & Bearing pressure of an arbitrary point \\
\hline Constant coefficient of Volterra series & Maximum value of applied pressure \\
\hline Foundation width & Net cone resistance \\
\hline Plate diameter & Corrected $q_{c}$ \\
\hline$C P T$ Cone penetration test & Ultimate bearing capacity \\
\hline Effective depth & $\begin{array}{l}\text { qult, } \text { Ultimate bearing capacity of the } \\
\text { foundation }\end{array}$ \\
\hline Embedment depth & $q_{\text {qult }, p}$ Ultimate bearing capacity of the plate \\
\hline Shaft resistance & $\begin{array}{ll}R_{f} & \text { Skin friction } \\
\end{array}$ \\
\hline Factor of safety & $\begin{array}{l}R_{k l} \quad \text { Coefficient for ultimate bearing } \\
\text { capacity calculation }\end{array}$ \\
\hline $\begin{array}{l}h_{s} \quad \text { Empirical fitting term that depends on } \\
\text { the soil type }\end{array}$ & $R M S E$ Root mean square error \\
\hline$I_{c} \quad$ Soil material index & Absolute fraction of variance \\
\hline Modulus of subgrade reaction & Settlement \\
\hline $\begin{array}{l}k_{s f} \text { Modulus of subgrade reaction of full- } \\
\text { sized footing }\end{array}$ & Allowable settlement \\
\hline $\begin{array}{ll}k_{s p} & \text { Modulus of subgrade reaction from } \\
P L T & \end{array}$ & Settlement of the foundation \\
\hline $\begin{array}{l}K_{\phi} \quad \text { Coefficient for ultimate bearing } \\
\text { capacity calculation }\end{array}$ & Allowable settlement of the foundation \\
\hline MAD Mean absolute deviation & Settlement of an arbitrary point \\
\hline Load & Settlement of the plate \\
\hline Allowable bearing capacity & Allowable settlement of the plate \\
\hline Cone tip resistance & Pore water pressure \\
\hline $\begin{array}{ll}q_{c, \text { ave }}, q_{c, \text { mean }} & \text { Averaged } C P T \text { cone } \\
\text { resistance } & \end{array}$ & $\alpha, \beta, \gamma$ Model parameters \\
\hline $\begin{array}{l}q_{\text {capacity }} \text { Foundation bearing capacity of the } \\
\text { ground }\end{array}$ & $\begin{array}{l}\sigma_{v o^{\prime}} \text { Effective overburden stress at bearing } \\
\text { elevation }\end{array}$ \\
\hline
\end{tabular}




\section{INTRODUCTION}

33 Load-settlement $(q-s)$ behavior of soils is commonly investigated by the plate load test (PLT)

34 through which the ultimate bearing capacity $\left(q_{u l t}\right)$ and allowable bearing capacity $\left(q_{a}\right)$ of shallow

35 foundations are determined. As a result of $P L T$, the settlement $(s)$ value is measured against the

36 specified applied pressure $(q)$, which consequently provides the basic geotechnical properties

37 required for the design of shallow foundations. Based on the PLT results, different criteria have

38 been suggested to compute $q_{u l t}$ from the $q$-s curves. In the study performed by Kulhawy (2004),

39 the loading corresponding to the settlement/width ratio of $0.1\left(\frac{s}{B}=0.1\right)$ was proposed to be $q_{u l t}$,

40 for all soil types except the sensitive clays, where the loading associated with $\frac{s}{B}=0.04$

41 introduces $q_{u l t}$. The mentioned criterion is well-known and distinguished in European standard

42 (Amar et al. 1998).

43 One of the consequential benefits from $q-s$ curves is the determination of the modulus of 44 subgrade reaction $\left(k_{s}\right)$, which is simply acquired from dividing the applied pressure by the 45 corresponding settlement $\left(k_{s}=\frac{q}{s}\right) . k_{s}$ can be suggested based on the allowable settlement 46 associated with different types of foundations, including shallow footings and mat foundations,

47 and according to various standards in different countries. It can also be suggested as the slope of

48 the initial tangent line to the load-settlement curve at zero settlement; yet, this definition is not

49 widely used in geotechnical engineering practice. Generally, the calculation of $k_{s}=\frac{q}{s}$ yields

50 more conservative designs in the former method, where it is dependent on the settlement level

51 and is effectively estimated for each specific allowable settlement value. In many previously

52 proposed correlations, like the one presented by Bowles (1996), $k_{s}$ is calculated for the settlement

53 of 1 inch which is simplified as the following relation: 
$54 \quad k_{s}=\frac{q_{u l t}}{s=1 \text { inch }(25 \mathrm{~mm})}=40 q_{u l t}=40 \times F S \times q_{a}$

55 where $F S$ is the safety factor and $q_{a}$ is the allowable bearing capacity.

56 It is worth noting that $k_{s}$ depends on some parameters like the shape and width of foundation as

57 well as the spatial variability of the stiffness/strength parameters of the soil underneath (Mohseni

58 et al. 2018). Vesic (1975) showed different values of $k_{s}$ for foundations having the same sizes

59 and applied pressures. Also, Farouk and Farouk (2014) indicated that the rigidity of the soil-

60 footing system should not be neglected for the determination of $k_{s}$. In terms of linear elastic

61 models, soil plasticity is ignored, which is the reason why the distribution of $k_{s}$ is anomalous at

62 the edges of the foundation. To allow for such an anomaly, non-linear models should be

63 employed. Terzaghi (1996) proposed $\boldsymbol{E} \boldsymbol{q}$. (2) in order to evaluate the modulus of subgrade

64 reaction of full-sized footings resting on sandy subgrades.

$65 \quad k_{s f}=k_{s p}\left(\frac{B_{p}+B_{f}}{2 B_{f}}\right)^{2}$

66 where $k_{s p}$ is the modulus of subgrade reaction from $P L T, k_{s f}$ is the corresponding value for the

67 actual foundation, $B_{p}$ is the plate diameter and $B_{f}$ is the foundation width.

68 Given the very fact that PLTs are costly and time-consuming, researchers have been recently

69 more inclined to invoke empirical relationships to yield $k_{s}$, the majority of which are endorsed by

70 in-situ tests (Naeini et al. 2018). A variety of field tests, amongst which the SPT and cone

71 penetration test $(C P T)$ are the most recent common ones, have garnered the attention of

72 researchers to provide experimental correlations for PLT parameters. So far, less attention has

73 been paid to the correlation between the results of PLT and CPT.

$74 C P T$ is one of the most useful common in-situ tests, which can lend itself to the prediction of 75 non-linear soil constitutive parameters, time-dependent stress-strain characteristics and profiling 
76 the soil elasto-plastic behavior (Holtz et al. 2011; Fellenius 2015). On the other hand, given the

77 very fact that repeatability is easily achieved in CPT soundings, and also that the accurate

78 stratification and soil layering interpretations are viable with $C P T$, even in small thicknesses, it is

79 therefore preferred amongst other common in-situ tests (Eslami et al. 2017, 2019).

80 Of late, the link between the PLT parameters and those of CPTs has been investigated in two

81 different categories, the first of which is to directly obtain the bearing capacity based on $C P T$

82 results and the second one is to predict the $q$-s curves through which $q_{u l t}$ can be estimated. In this

83 article, the second category is adopted. The proposed methods and relationships for the

84 determination of the ultimate bearing capacity from $C P T$ results are enlisted in Table $\mathbf{1}$ in

85 chronological order (Saftner and Dagger 2018).

Table 1. Recent direct $C P T$ methods to calculate the bearing capacity of footings on clean sands (Saftner and Dagger 2018).

\begin{tabular}{|c|c|c|}
\hline Method & Surface footing & Remarks and embedment \\
\hline \multirow[b]{2}{*}{ Eslami \& Gholami (2006) } & \multirow[b]{2}{*}{$q_{u l t}=R_{k 1} \times q_{c}$} & where $R_{k l}$ is a function of $D_{f} / B$ and $q_{c} / \sigma_{v o}{ }^{\prime}$ \\
\hline & & $\begin{array}{c}\text { Note: Measured } q_{c} \text { and } q_{c} / \sigma_{v o}{ }^{\prime} \text { are geometric means } \\
\text { Influence zone: Depth of } 2 B \text { beneath footing }\end{array}$ \\
\hline Briaud (2007) & $\begin{array}{c}q_{u l t}=K_{\phi} \times q_{c} \\
\left(K_{\phi}=0.23\right)\end{array}$ & $\begin{array}{c}\text { Based on full-scale tests at Texas A\&M University } \\
\text { Influence zone: Depth of } 2 B \text { beneath footing }\end{array}$ \\
\hline Robertson \& Cabal (2014) & $\begin{array}{c}q_{u l t}=K_{\phi} \times q_{c} \\
\left(K_{\phi}=0.16\right)\end{array}$ & $\begin{array}{c}\text { Where } \mathrm{K}_{\phi} \text { is a function of } B / D_{e} \text {, shape, and density } \\
\text { Influence zone: Depth of } 2 B \text { beneath footing }\end{array}$ \\
\hline \multirow[b]{2}{*}{ Mayne \& Illingworth (2010) } & \multirow{2}{*}{$q_{u l t}=0.18 q_{c, \text { mean }}$} & Based on 30 footing load tests on 12 sands \\
\hline & & $\begin{array}{l}\text { Note: } q_{c, \text { mean }} \text { is averaged } C P T \text { cone resistance } \\
\text { Influence zone: Depth of } 1.5 B \text { beneath footing }\end{array}$ \\
\hline \multirow[b]{2}{*}{ Lehane (2012) } & \multirow[b]{2}{*}{$q_{u l t}=0.16 q_{c, a v e}$} & Based on 47 load tests \\
\hline & & $\begin{array}{c}\text { Note: } q_{c, \text { ave }} \text { is averaged } C P T \text { cone resistance } \\
\text { Influence zone: }[B(\mathrm{~m})]^{0.7}\end{array}$ \\
\hline
\end{tabular}


89 Deploying CPT results, many researchers have tried to correlate $q$ to the dimensionless

90 parameter, $\frac{s}{B}$, which consequently has resulted the following general formula (Fellenius and

$91 \quad$ Altaee 1994; Decourt 1999; Briaud 2007).

$92 \quad q=a_{f}\left(\frac{S}{B}\right)^{b_{f}}$

93 Where $\mathrm{q}$ is the footing bearing pressure, $s / B$ is the footing settlement normalized against the

94 footing width $\mathbf{B}$, and $a_{f}$ and $b_{f}$ are the model parameters. Based on Mayne et al. (2012), the

95 value of $b_{f}$ was suggested to be 0.5 , and the value of $a_{f}$ for sands was reported to be dependent on

96 the particle size distribution, relative density, geological condition and the percentage of fine

97 grains. Regarding the ultimate bearing capacity criterion for sandy soils, when $\frac{s}{B}=0.1, q_{u l t}$

98 equates to $0.316 a_{f}$. Based on the theoretical studies conducted by Briaud (2007) and Mayne $\boldsymbol{e t}$

99 al. (2012), Eq. (4) was proposed using $32 q-s$ data sets on 13 different soil types (note that $q_{c}$ is

100 the cone tip resistance).

$101 \quad q=0.585 q_{c} \sqrt{\frac{S}{B}}$

102 Stuedlein and Holtz (2010) assigned 1.77 MPa for $a_{f}$ of the soil known as delta soil, yet it

103 should be noted that the number of the studied data was quite limited. Uzielli and Mayne (2011)

104 used $q_{\text {net }}$ instead of $q_{c}$ in $\boldsymbol{E q}$. (4) and rewrote it as $\boldsymbol{E q}$. (5).

$105 q=h_{s} q_{\text {net }}\left(\frac{S}{B}\right)^{0.5}<q_{\text {capacity }}$

106 where $q_{n e t}$ is the net cone resistance, $q_{\text {capacity }}$ is the foundation bearing capacity of the ground and

$107 h_{s}$ is the empirical fitting term which was considered to be $0.58,1.12,1.47$ and 2.7 , for sands,

108 silts, crushed (fissured) soils and clays, respectively. It is worth noting that the value of $q_{\text {capacity }}$ is 
109 approximately close to the maximum value of $q$ in the load-displacement profile $\left(q_{\max }\right)$. Mayne

110 (2014) incorporated the soil material index, $I_{c}$, as an indicative of the type of soil behavior, into

111 the other empirical relationships and proposed a correlation which could predict the $q$ - $s$ trend

112 (Eq. (6)).

$113 q=q_{\text {net }} \sqrt{\frac{S}{B}}\left[2.8-\frac{2.3}{1+\left(\frac{I_{C}}{2.4}\right)^{15}}\right]$

114 Most researchers, who have previously studied the relationship between $q$-s profiles and $C P T$

115 results, have confirmed that $q$ is an a priori function of $\left(\frac{S}{B}\right)^{0.5}$ based on the correlations they have

116 presented whose differences lay solely on the magnification factor. However, the mentioned

117 relationships are open to question as $q$ grows excessively in higher settlements. Their proposed

118 correlations were therefore more acceptable for the values of $\frac{s}{B}$ up to 0.1 , beyond which they

119 would render unrealistic $q$ values. In this study, an attempt has been made to reconcile this by

120 establishing a novel and more appealing model, which could intrinsically capture the limiting

121 nature of the bearing pressure.

122 Generally, it should be noted that the $q$-s curves in this study were obtained from reliable sources 123 including $46 P L T$ s and their corresponding $C P T$ logs. In the following sections, first, the 124 collected database and the input and output variables are explained and then, the results of the 125 modeling are provided in terms of equations and predicted versus measured trends of $q$-s. Also, 126 the validation of the proposed hyperbolic function, and the comparison with previous models are 127 discussed and the variations of $q_{u l t}, q_{a}$ and $k_{s}$ with $C P T$ parameters are thoroughly elaborated. 128 Finally, sensitivity analysis of the input variables is presented. 
130 Naturally, in $q$-s curves, values of the imposed pressure tend to be bounded to two extremes. In

131 the suggested models, two different boundary conditions are expected for the lower extreme

$132(s \rightarrow 0)$ and the higher extreme $(s \rightarrow+\infty)$, where $q$ tends to 0 and $q_{\max }$, respectively.

133 There are some limitations associated with the previous models, including failure to incorporate

134 the asymptotic behavior at limit settlements $(s \rightarrow+\infty)$; hence, suggesting the need for simpler

135 models with far superior applicability. It should be noted that the proposed function $q=f(s)$ to

136 fit a PLT load-displacement profile should meet the following conditions: $f(0)=0, f^{\prime}(0)$

137 should be the global maximum, and $f^{\prime}(\infty) \approx 0$ should be satisfied. Therefore, it is deemed that

138 if a function meets the aforementioned criteria and is capable of precise prediction of the $q-s$

139 curve, it can accurately serve to estimate the $q_{\max }, q_{u l t}, q_{a}$ and $k_{s}$ parameters, as schematically

140 illustrated in Figure 1.

141 Many functions have been proposed to predict the load-settlement behavior of geo-materials 142 amongst which the hyperbolic function has been admittedly used effectively in analyzing

143 geotechnical properties, such as predicting the settlement, assessing the compressibility behavior

144 and describing the relationship between the void ratio and effective stress (Al-Shamrani 2005;

145 Sridharan 2006; Zhang et al. 2014; Ahmed and Siddiqua 2016; Soltani et al. 2017; Liu and

146 Zheng 2019). Upon reviewing the literature, to the best of the authors' knowledge, very limited

147 efforts have been devoted to the prediction of the $q-s$ behavior of shallow footings on the basis of

$148 C P T$ records using the hyperbolic function. The hyperbolic function considered in the present

149 paper is given in $\boldsymbol{E q}$. (7), which has three constant coefficients.

$150 \quad q(s)=\frac{\alpha s}{\beta s+\gamma}$

151 boundary conitions $\left\{\begin{array}{c}q(0)=0 \\ \lim _{s \rightarrow+\infty} q(s) \approx \frac{\alpha}{\beta}\end{array}\right.$ 
152 where $\alpha, \beta$ and $\gamma$ are the model parameters, which can be obtained from PLT results using 153 regression analysis. Schematic illustration of the proposed hyperbolic model is depicted in 154 Figure 1 along with the index parameters.

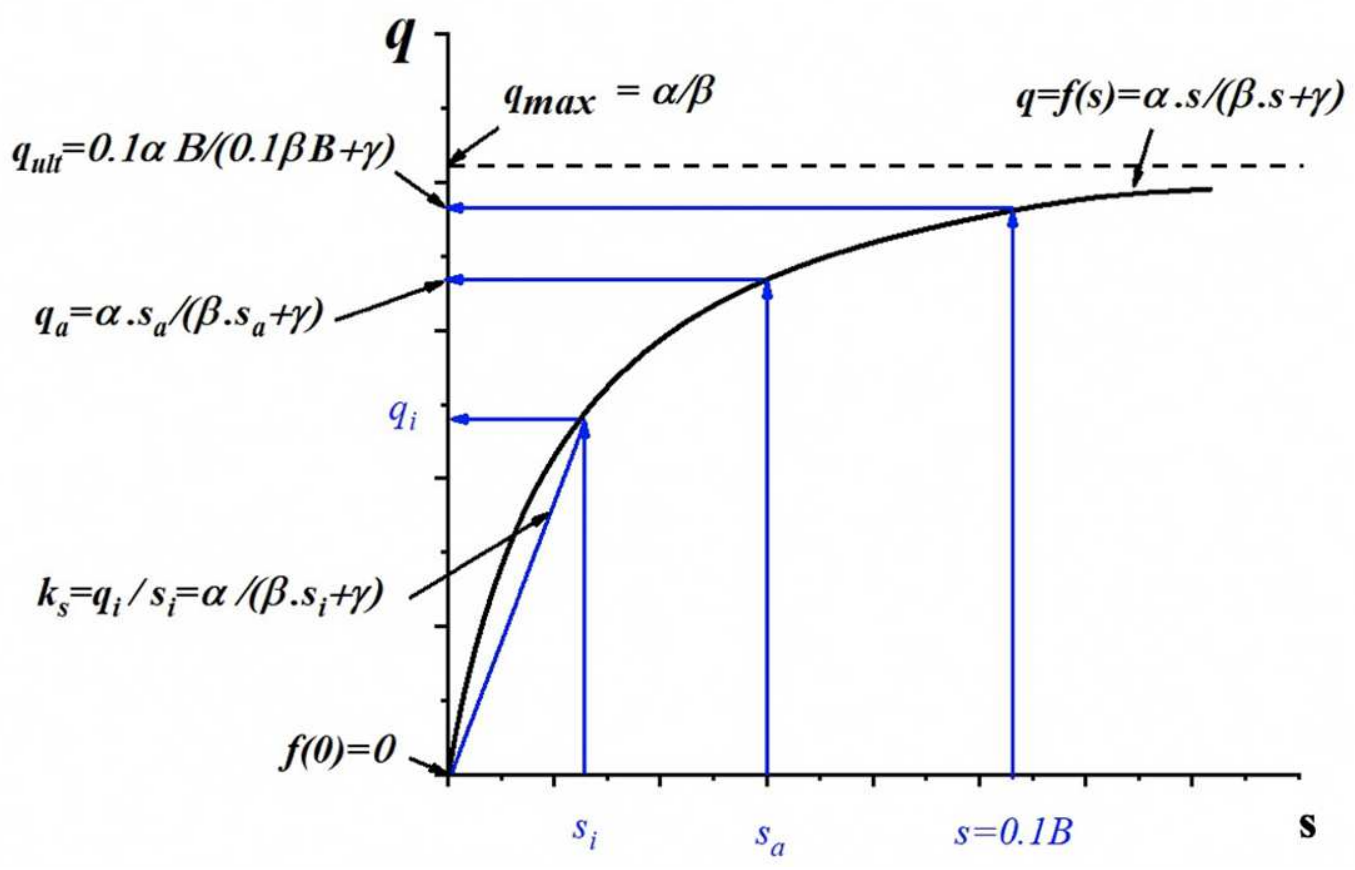

Figure 1. Schematic illustration of the hyperbolic function.

157 As shown in Figure 1, $q_{\max }$ is defined as the horizontal asymptotic of the bearing pressure

158 function, $q_{u l t}$ is the value of bearing capacity corresponding to $\frac{s}{B}=0.1, q_{a}$ is the allowable

159 bearing capacity equivalent to the allowable settlement $\left(s_{a}\right)$ and $k_{s}$ is the slope of the line starting 160 at the origin and ending at the arbitrary point with the settlement of $s_{i}$ and the bearing pressure of $161 q_{i}$

$162 C P T$ strength measurement is based on the soil failure with respect to the cone penetration, 163 which is driven consistently and at a slow pace. Such properties presumably make $C P T$ one of 164 the most viable options among the in-situ tests to determine the above-mentioned hyperbolic 165 model parameters. Herein, by adopting some $C P T$ records, $\alpha, \beta$ and $\gamma$ can be estimated as the 
166 main contribution of the current paper that can be suggested from the load-displacement profiles

167 of PLT. In other words, these parameters are linked to $q_{\max }, q_{u l t}, q_{a}$ and $k_{s}(\boldsymbol{E q s}$. $(\mathbf{8 a})$ to $(8 \boldsymbol{d}))$.

$168 \quad q_{\max }=\frac{\alpha}{\beta}$

$169 \quad q_{u l t}=\frac{0.1 \alpha B}{0.1 \beta B+\gamma}$

$170 \quad q_{a}=\frac{\alpha s_{a}}{\beta s_{a}+\gamma}$

$171 \quad k_{s}=\frac{\alpha}{\beta s+\gamma}$

172 where $\alpha, \beta$ and $\gamma$ can be presented as functions of the cone tip and shaft resistances, $q_{c}$ and $f_{s}$.

173 Therefore, with the $C P T$ records at hand, model parameters $\alpha, \beta$ and $\gamma$ can be predicted

174 accordingly. By and large, a general model can be established to estimate the $q$-s profile on the

175 basis of a database containing $C P T$ and $P L T$ results.

176 It is important to note that the foundation width $(B)$ is also considered in the modeling. To this

177 end, $\frac{S}{B}$ has been used to consider the effect of the plate dimension. This makes the settlement

178 dimensionless consistent with previous studies like Mayne and Dasenbrock (2018). Ergo, Eq.

179 (7) could be rewritten as follows:

$180 \quad q(s)=\frac{\alpha \frac{s}{B}}{\beta \frac{S}{B}+\gamma}$

181 Although $\alpha, \beta$ and $\gamma$ are primarily functions of $q_{c}$ and $f_{s}$, they are assumed to be functions of $q_{t}$

182 and $R_{f}$ herein to take the influence of pore water pressure into account. Hence, $q_{t}$ (corrected cone

183 resistance) could be defined as:

$184 \mathrm{q}_{\mathrm{t}}=\mathrm{q}_{\mathrm{c}}+\mathrm{u}_{2}(1-\mathrm{a})$

185 where $u_{2}$ is the pore water pressure and $a$ is the net area ratio of cone tip. 
186 Hence, in terms of the dimensional analysis for the hyperbolic model parameters, shown in $\boldsymbol{E} \boldsymbol{q}$. 187 (9), the unit of $\alpha$ is $k P a$, and $\beta$ and $\gamma$ are both dimensionless. It is worth noting that the effect of 188 embedment depth, $D_{f}$ is reflected in $q_{t}$ in such a way that the more the depth of the foundation, 189 the more effectively it will impact $q_{t}$. In general, the current study seeks to validate the 190 hyperbolic model and derive a relationship between the model and CPT parameters.

\section{3. REVIEW OF THE DATABASE}

192 The experimental data employed for the validation of $\boldsymbol{E q}$. (9) were gathered from credible

193 sources, including $46 C P T$ logs and $46 q$-s results from PLTs. Furthermore, other parameters like

194 the footing width $(B)$ and embedment depth $\left(D_{f}\right)$ of the PLTs were documented. For CPT data, 195 the depth of $2 B$ has been regarded as the effective zone of load influence, according to the 196 majority of the common methods for the estimation of the settlement beneath the foundation 197 under symmetric loading (Valikhah and Eslami 2019). The parameters acquired from CPT and 198 used in the analyses are the tip resistance $q_{t}\left(q_{c}\right.$ corrected for pore pressure) and skin friction

$199\left(R_{f}=\frac{f_{s}}{q_{c}}\right)$. The mentioned CPT parameters were introduced in an arithmetic average sense 200 through a depth of $2 B$ so as to reflect the mean soil shear strength (Eslami and Mohammadi 201 2016). Based on the soil and loading conditions and according to Schmertmann (1978), the 202 effective depth under the foundation is equal to approximately $2 B$. Table 2 lists the experimental 203 data related to a series of tests performed on a wide range of soil types, from silty clays to sands.

204 The parameter $q_{u l t}$ is reported corresponding to $s / B \cong 0.1$.

205 On the other hand, for any of the $q$-s curves in different cases, several data points with respect to 206 various settlements were considered as the values for the input parameter, and the amount of 207 pressure was considered as the output. Bar charts of the data are depicted in Figure 2, where the 
208 vertical axis is the relative frequency. As shown in Figure 2, the data covers a wide range of $209 C P T$ values, which belong to silty clays and sands.
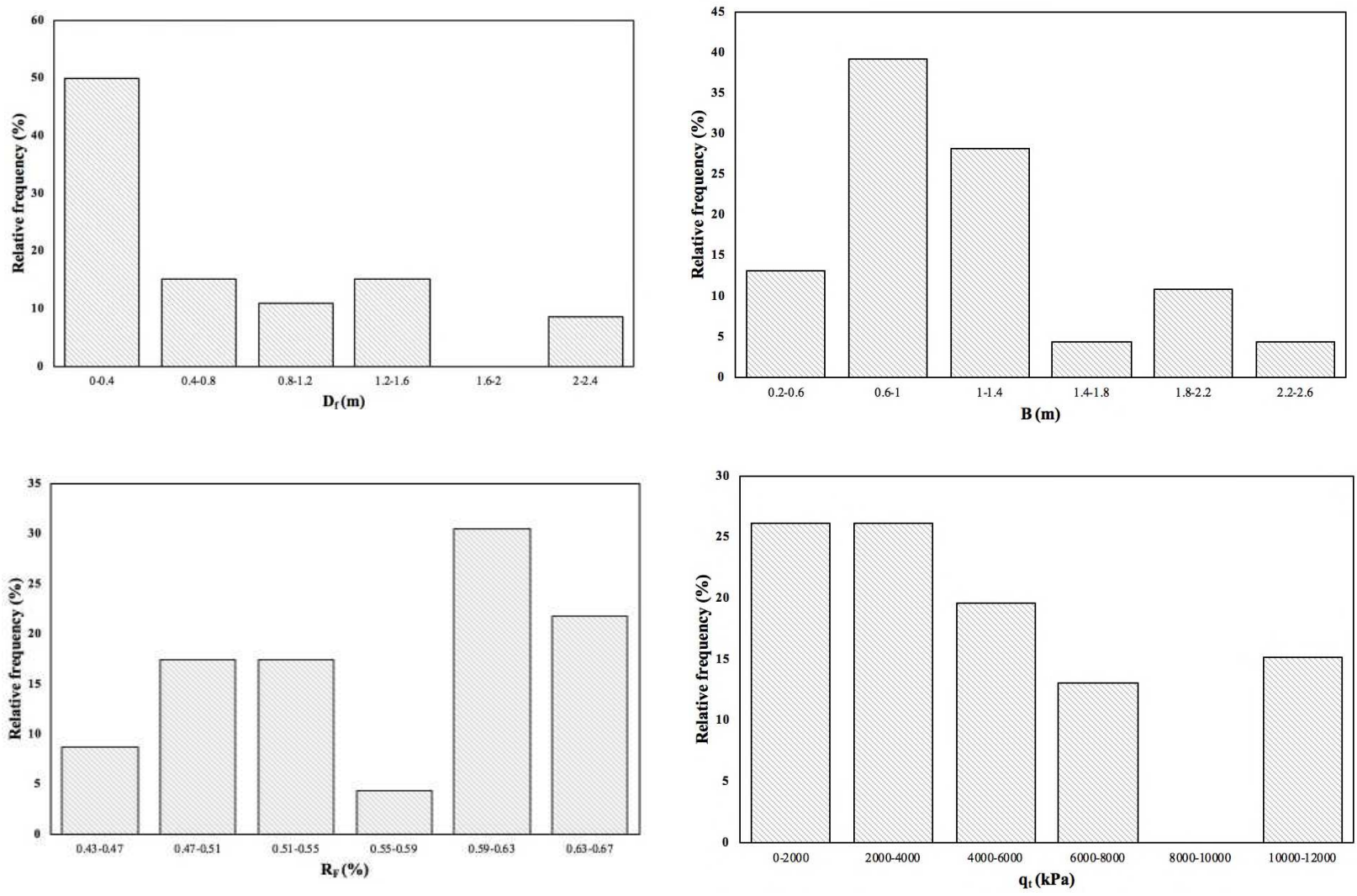

Figure 2. Bar charts of the input variables.

211

212

Table 2. A summary of the data employed in this research.

\begin{tabular}{|c|c|c|c|c|c|c|c|c|c|c|}
\hline \multirow{2}{*}{ Soil Type } & \multirow{2}{*}{$\begin{array}{l}\text { Case } \\
\text { No. }\end{array}$} & \multirow{2}{*}{$\begin{array}{l}\text { Footing } \\
\text { Shape }\end{array}$} & \multicolumn{2}{|c|}{ from CPT } & \multicolumn{5}{|c|}{ from PLT } & \multirow{2}{*}{ Reference } \\
\hline & & & $\begin{array}{c}\mathbf{q}_{\mathbf{t}} \\
(\mathbf{k P a})\end{array}$ & $\mathbf{R}_{\mathbf{f}}$ & $D_{f}(\mathbf{m})$ & $\mathbf{B}(\mathbf{m})^{*}$ & $\mathbf{L} / \mathbf{B}$ & $\begin{array}{c}\mathbf{q u l t} \\
(\mathbf{k P a})\end{array}$ & $\begin{array}{c}\mathbf{S} \\
(\mathbf{m m}) \\
\end{array}$ & \\
\hline \multirow{2}{*}{ Silt } & N1 & \multirow{2}{*}{ Square } & 2500 & 0.5 & 0 & 1 & 1 & 300 & 98 & \multirow{9}{*}{$\begin{array}{c}\text { Eslami and } \\
\text { Gholami (2006) }\end{array}$} \\
\hline & $\mathrm{N} 2$ & & 2800 & 0.5 & 0 & 1 & 1 & 325 & 97 & \\
\hline \multirow{2}{*}{ Silty Sand } & N3 & \multirow{2}{*}{ Square } & 7000 & 0.5 & 0 & 0.6 & 1 & 1260 & 55 & \\
\hline & $\mathrm{N} 4$ & & 10000 & 0.5 & 0 & 0.6 & 1 & 1280 & 55 & \\
\hline \multirow{3}{*}{ Silty Clay } & N5 & \multirow{3}{*}{ Circular } & 1400 & 0.6 & 0 & 0.45 & 1 & 170 & 40 & \\
\hline & N6 & & 1700 & 0.6 & 0 & 0.6 & 1 & 170 & 55 & \\
\hline & N7 & & 2000 & 0.6 & 0 & 0.6 & 1 & 170 & 55 & \\
\hline \multirow{2}{*}{ Silty Clay } & N8 & \multirow{2}{*}{ Circular } & 3100 & 0.6 & 1.5 & 0.6 & 1 & 520 & 60 & \\
\hline & N9 & & 4600 & 0.6 & 1.5 & 0.6 & 1 & 310 & 55 & \\
\hline
\end{tabular}




\begin{tabular}{|c|c|c|c|c|c|c|c|c|c|c|}
\hline & \multirow{2}{*}{$\begin{array}{l}\text { N10 } \\
\text { N11 }\end{array}$} & & \multirow{2}{*}{$\begin{array}{l}5400 \\
6000\end{array}$} & 0.6 & 1.5 & 0.6 & 1 & 310 & 60 & \\
\hline & & & & 0.6 & 1.5 & 0.6 & 1 & 690 & 60 & \\
\hline \multirow{4}{*}{$\begin{array}{l}\text { Glaciofluvial } \\
\text { Sand }\end{array}$} & N12 & \multirow{4}{*}{ Rectangular } & 10720 & 0.51 & 0.4 & 0.6 & 1.18 & 1740 & 59 & \multirow{5}{*}{$\begin{array}{l}\text { Mayne and } \\
\text { Illingworth } \\
\quad(\mathbf{2 0 1 0})\end{array}$} \\
\hline & N13 & & 10720 & 0.51 & 0.6 & 1.2 & 1.1 & 1740 & 119 & \\
\hline & N14 & & 10720 & 0.51 & 0.8 & 1.7 & 1.12 & 1740 & 170 & \\
\hline & N15 & & 10720 & 0.51 & 1.1 & 2.4 & 1.08 & 1740 & 245.8 & \\
\hline Siliceous Sand & N16 & Square & 3440 & 0.44 & 0.5 & 0.5 & 1 & 480 & 51 & \\
\hline \multirow{2}{*}{ Sand, Silty Sand } & N17 & \multirow{2}{*}{ Square } & 7520 & 0.65 & 0.76 & 1 & 1 & 1540 & 100 & \multirow{2}{*}{$\begin{array}{c}\text { Briaud and } \\
\text { Gibbens (1999) }\end{array}$} \\
\hline & N18 & & 7520 & 0.65 & 0.76 & 1.5 & 1 & 1540 & 154 & \\
\hline \multirow{2}{*}{ Silt } & N19 & \multirow{2}{*}{ Square } & 1700 & 0.5 & 0 & 1 & 1 & 375 & 115 & \multirow{8}{*}{$\begin{array}{c}\text { Eslami and } \\
\text { Gholami (2006 }\end{array}$} \\
\hline & $\mathrm{N} 20$ & & 2000 & 0.5 & 0 & 1 & 1 & 370 & 100 & \\
\hline Silty Sand & $\mathrm{N} 21$ & Square & 3000 & 0.5 & 0 & 0.6 & 1 & 1260 & 60 & \\
\hline \multirow{2}{*}{ Silty Clay } & $\mathrm{N} 22$ & \multirow{2}{*}{ Circular } & 500 & 0.6 & 0 & 0.3 & 1 & 170 & 33 & \\
\hline & $\mathrm{N} 23$ & & 900 & 0.6 & 0 & 0.3 & 1 & 170 & 25 & \\
\hline \multirow{3}{*}{ Silty Clay } & $\mathrm{N} 24$ & \multirow{3}{*}{ Circular } & 1000 & 0.6 & 1.5 & 0.6 & 1 & 600 & 72 & \\
\hline & $\mathrm{N} 25$ & & 1700 & 0.6 & 1.5 & 0.6 & 1 & 600 & 72 & \\
\hline & $\mathrm{N} 26$ & & 2500 & 0.6 & 1.5 & 0.6 & 1 & 600 & 60 & \\
\hline $\begin{array}{l}\text { White Fine } \\
\text { Sand }\end{array}$ & $\mathrm{N} 27$ & Square & 3660 & 0.54 & 0 & 0.69 & 1 & 620 & 65 & \\
\hline \multirow{3}{*}{$\begin{array}{l}\text { Glaciofluvial } \\
\text { Sand }\end{array}$} & $\mathrm{N} 28$ & \multirow{3}{*}{ Rectangular } & 4010 & 0.63 & 0 & 1 & 1.02 & 840 & 102.4 & \\
\hline & $\mathrm{N} 29$ & & 4010 & 0.63 & 0 & 1 & 1.02 & 840 & 102.4 & \\
\hline & $\mathrm{N} 30$ & & 3200 & 0.63 & 1.1 & 2.4 & 1.08 & 640 & 260 & \\
\hline & N31 & & 880 & 0.53 & 0 & 0.46 & 1 & 150 & 47 & \\
\hline Compacted Fill & N32 & Square & 3860 & 0.48 & 0 & 0.63 & 1 & 580 & 64 & \\
\hline & N33 & & 2870 & 0.58 & 0 & 0.8 & 1 & 520 & 82 & \\
\hline & N34 & & 6720 & 0.6 & 2.2 & 2.2 & 1 & 1280 & 250 & \\
\hline Alluvial Sand & N35 & Circular & 6720 & 0.6 & 2.2 & 2.2 & 1 & 1280 & 250 & \\
\hline Amuviar Dantu & N36 & Cirtural & 10460 & 0.52 & 2.35 & 2.35 & 1 & 1730 & 245 & Illingworth \\
\hline & N37 & & 10460 & 0.52 & 2.35 & 2.35 & 1 & 1730 & 245 & (2010) \\
\hline & N38 & & 4010 & 0.66 & 0 & 0.7 & 1 & 840 & 71.7 & \\
\hline & N39 & & 4010 & 0.66 & 0 & 0.7 & 1 & 840 & 71.7 & \\
\hline Dune Sand & $\mathrm{N} 40$ & Square & 4010 & 0.66 & 0 & 1 & 1 & 840 & 102.4 & \\
\hline & N41 & & 4010 & 0.66 & 0 & 1 & 1 & 840 & 102.4 & \\
\hline & N42 & & 4010 & 0.66 & 0 & 1 & 1 & 840 & 102.4 & \\
\hline Silty Sand & $\mathrm{N} 43$ & Circular & 1710 & 0.55 & 0.6 & 1.82 & 1 & 1710 & 186 & \\
\hline & N44 & & 480 & 0.44 & 0.5 & 0.5 & 1 & 480 & 51 & \\
\hline $\begin{array}{l}\text { Siliceous Dune } \\
\text { Sand }\end{array}$ & N45 & Square & 480 & 0.44 & 1 & 1 & 1 & 480 & 102 & \\
\hline & N46 & & 480 & 0.44 & 1 & 1 & 1 & 480 & 102 & \\
\hline
\end{tabular}

$213{ }^{*} B$ is considered as the width and the diameter of the square and circular footings, respectively. 
214 The main scope of this paper is the examination of the relationships between $C P T$ and load-

215 settlement parameters. It is worth noting that several geotechnical parameters could be estimated

216 from CPT data, as highlighted in a number of previous studies (Eslami et al. 2019).

\section{4. RESULTS}

\section{4.1. Hyperbolic model for load-displacement profiles}

219 Based on the presented database, 46 PLTs were selected from the literature whose results were 220 then fitted by the well-established hyperbolic model. The selected data set was compiled from all

221 over the globe and was not restricted to a specific location so as to introduce sufficient diversity.

222 The fitting parameters, including $\alpha, \beta$ and $\gamma$, were computed based on the least squares error

223 optimization scheme. Table 3 enlists the parameters for all the 46 cases. Furthermore, absolute

224 fraction of variance $\left(R^{2}\right)$, root mean square error (RMSE) and mean absolute deviation $(M A D)$ are 225 defined in Eqs. (11), (12) and (13), respectively, and were exploited herein to assess the fitting 226 accuracy of the relevant correlations.

$227 \quad R^{2}=1-\left[\frac{\sum_{1}^{M}\left(\mathrm{q}_{m i}-\mathrm{q}_{c i}\right)^{2}}{\sum_{1}^{M}\left(\mathrm{q}_{m i}\right)^{2}}\right]$

$228 \quad R M S E=\sqrt{\frac{1}{M} \sum_{1}^{M}\left(\mathrm{q}_{m i}-\mathrm{q}_{c i}\right)^{2}}$

$229 M A D=\frac{\sum_{1}^{M}\left|\mathrm{q}_{m i}-\mathrm{q}_{c i}\right|}{M}$

230 where $q_{m i}$ and $q_{c i}$ are the measured and calculated pressures, respectively. Lower values of $R M S E$

231 and $M A D$ (close to zero) and higher values of $R^{2}$ (close to one) are indicators of superior model

232 performance. Table 3 corroborates the accuracy of $\boldsymbol{E q}$. (9) in replicating the load-displacement

233 trends acquired from PLTs, substantiated in forms of high $R^{2}$ and low $R M S E$ and MAD values.

234 To be more specific, the $R^{2}$ values have remained higher than $99 \%$ and the $R M S E$ and $M A D$

235 values are lower than 34 and $17 \mathrm{kPa}$, respectively; hence, bearing witness to the efficacy of $\boldsymbol{E q}$. 
236 (9). It should be noted that $k_{s 0}$ is the maximum modulus of subgrade reaction, values of $q_{a}$ and $k_{s}$

237 are corresponding to $\frac{S}{B}=0.05$, and $q_{\max }$ is the asymptotic load.

238 Table 3. Summary of the regression analyses for the hyperbolic model, encapsulating all the studied data.

\begin{tabular}{|c|c|c|c|c|c|c|c|c|c|c|}
\hline Case No. & $\begin{array}{c}\alpha \\
(\mathbf{M P a})\end{array}$ & $\boldsymbol{\beta}$ & $\gamma$ & $\mathbf{R}^{2}$ & $\begin{array}{c}\text { RMSE } \\
\text { (kPa) }\end{array}$ & $\begin{array}{l}\text { MAD } \\
(\mathbf{k P a})\end{array}$ & $\begin{array}{c}\mathbf{q m a x}_{\max } \\
(\mathbf{k P a})\end{array}$ & $\begin{array}{c}\mathbf{q}_{\mathbf{a}}(\mathbf{k P a}) \\
(\mathrm{s} / \mathbf{B}=\mathbf{0 . 0 5})\end{array}$ & $\begin{array}{c}\mathbf{k s}_{\mathbf{0}} \\
\left(\mathrm{MN} / \mathbf{m}^{3}\right)\end{array}$ & $\begin{array}{c}\mathrm{ks}\left(\mathrm{MN} / \mathrm{m}^{3}\right) \\
(\mathrm{s} / \mathrm{B}=0.05)\end{array}$ \\
\hline $\mathrm{N} 1$ & 59 & 168.0 & 2.65 & 0.99 & 4 & 9 & 348 & 265 & 22 & 5 \\
\hline $\mathrm{N} 2$ & 62 & 162.4 & 2.62 & 0.99 & 5 & 9 & 379 & 286 & 23 & 6 \\
\hline N3 & 247 & 167.0 & 2.67 & 0.99 & 17 & 9 & 1480 & 1121 & 154 & 22 \\
\hline N4 & 277 & 170.3 & 2.70 & 0.98 & 34 & 15 & 1628 & 1236 & 171 & 25 \\
\hline N5 & 34 & 168.9 & 2.69 & 0.99 & 2 & 9 & 200 & 152 & 28 & 3 \\
\hline N6 & 32 & 162.1 & 2.62 & 0.99 & 2 & 9 & 200 & 151 & 21 & 3 \\
\hline N7 & 33 & 170.2 & 2.70 & 0.99 & 2 & 9 & 197 & 149 & 21 & 3 \\
\hline N8 & 101 & 166.1 & 2.66 & 0.99 & 8 & 10 & 609 & 461 & 63 & 9 \\
\hline N9 & 62 & 169.4 & 2.69 & 0.99 & 4 & 9 & 364 & 276 & 38 & 6 \\
\hline N10 & 60 & 165.5 & 2.66 & 0.99 & 4 & 9 & 360 & 272 & 37 & 5 \\
\hline N11 & 135 & 169.3 & 2.69 & 0.99 & 10 & 10 & 800 & 607 & 84 & 12 \\
\hline N12 & 307 & 163.7 & 2.64 & 0.99 & 17 & 8 & 1877 & 1419 & 194 & 28 \\
\hline N13 & 307 & 168.9 & 2.69 & 0.99 & 20 & 9 & 1819 & 1380 & 95 & 28 \\
\hline N14 & 307 & 165.1 & 2.65 & 0.99 & 17 & 8 & 1861 & 1409 & 68 & 28 \\
\hline N15 & 307 & 161.3 & 2.61 & 0.997 & 17 & 8 & 1905 & 1439 & 49 & 29 \\
\hline N16 & 87 & 166.3 & 2.66 & 0.997 & 5 & 8 & 521 & 394 & 65 & 8 \\
\hline N17 & 267 & 163.7 & 2.64 & 0.996 & 16 & 8 & 1633 & 1235 & 101 & 25 \\
\hline N18 & 267 & 169.8 & 2.70 & 0.994 & 20 & 9 & 1574 & 1194 & 66 & 24 \\
\hline N19 & 73 & 170.8 & 2.71 & 0.989 & 7 & 12 & 427 & 324 & 27 & 6 \\
\hline N20 & 58 & 163.5 & 2.63 & 0.994 & 8 & 17 & 357 & 270 & 22 & 5 \\
\hline N21 & 236 & 161.2 & 2.61 & 0.993 & 18 & 9 & 1464 & 1106 & 151 & 22 \\
\hline $\mathrm{N} 22$ & 32 & 165.6 & 2.66 & 0.991 & 3 & 10 & 195 & 147 & 40 & 3 \\
\hline N23 & 33 & 163.4 & 2.63 & 0.995 & 2 & 11 & 203 & 153 & 42 & 3 \\
\hline N24 & 116 & 171.0 & 2.71 & 0.988 & 11 & 13 & 678 & 515 & 71 & 10 \\
\hline N25 & 115 & 168.6 & 2.69 & 0.988 & 11 & 13 & 680 & 515 & 71 & 10 \\
\hline N26 & 115 & 166.3 & 2.66 & 0.994 & 8 & 9 & 692 & 524 & 72 & 10 \\
\hline N27 & 101 & 165.5 & 2.65 & 0.985 & 13 & 17 & 612 & 464 & 55 & 9 \\
\hline $\mathrm{N} 28$ & 138 & 164.7 & 2.65 & 0.990 & 14 & 12 & 837 & 633 & 52 & 13 \\
\hline $\mathrm{N} 29$ & 138 & 168.5 & 2.68 & 0.987 & 16 & 14 & 818 & 620 & 51 & 12 \\
\hline $\mathrm{N} 30$ & 114 & 167.0 & 2.67 & 0.997 & 6 & 7 & 680 & 515 & 18 & 10 \\
\hline N31 & 29 & 170.7 & 2.71 & 0.995 & 2 & 9 & 170 & 129 & 23 & 3 \\
\hline $\mathrm{N} 32$ & 97 & 170.9 & 2.71 & 0.988 & 11 & 13 & 570 & 432 & 57 & 9 \\
\hline
\end{tabular}




\begin{tabular}{|l|c|c|c|c|c|c|c|c|c|c|}
\hline N33 & 90 & 162.6 & 2.63 & 0.996 & 5 & 8 & 552 & 417 & 43 & 8 \\
\hline N34 & 212 & 167.4 & 2.67 & 0.993 & 18 & 8 & 1266 & 960 & 36 & 19 \\
\hline N35 & 212 & 161.3 & 2.61 & 0.996 & 14 & 7 & 1314 & 992 & 37 & 20 \\
\hline N36 & 303 & 166.9 & 2.67 & 0.996 & 18 & 7 & 1815 & 1375 & 48 & 28 \\
\hline N37 & 303 & 162.4 & 2.62 & 0.997 & 16 & 8 & 1865 & 1410 & 49 & 28 \\
\hline N38 & 150 & 170.9 & 2.71 & 0.996 & 9 & 8 & 880 & 668 & 79 & 13 \\
\hline N39 & 150 & 167.7 & 2.68 & 0.997 & 8 & 8 & 897 & 680 & 80 & 14 \\
\hline N40 & 150 & 162.8 & 2.63 & 0.997 & 8 & 8 & 924 & 698 & 57 & 14 \\
\hline N41 & 150 & 161.3 & 2.61 & 0.996 & 9 & 8 & 932 & 704 & 58 & 14 \\
\hline N42 & 150 & 169.2 & 2.69 & 0.997 & 8 & 8 & 889 & 674 & 56 & 13 \\
\hline N43 & 327 & 165.5 & 2.66 & 0.993 & 25 & 9 & 1976 & 1495 & 68 & 30 \\
\hline N44 & 90 & 162.5 & 2.63 & 0.993 & 7 & 9 & 554 & 418 & 68 & 8 \\
\hline N45 & 89 & 161.2 & 2.61 & 0.994 & 7 & 9 & 552 & 417 & 34 & 8 \\
\hline N46 & 91 & 164.5 & 2.64 & 0.993 & 7 & 9 & 553 & 419 & 34 & 8 \\
\hline
\end{tabular}

239

240 Maximum soil strength means that the soil has reached the failure state or is on the verge of

241 failure. $C P T$ has also the same mechanism with its resistance parameters $\left(R_{f}\right.$ and $\left.q_{t}\right)$ being

242 equivalent to the soil failure state. Based on the experimental and numerical studies, a

243 logarithmic spiral failure mode has been considered for the $C P T$ results of homogenous soils as

244 shown in Figure 3. According to Eslami and Mohammadi (2016), the failure mechanism of

$245 C P T$ tests is approximately similar to that of shallow foundations. Therefore, it can be observed

246 that the pressure corresponding to the ultimate bearing capacity state or the same failure

247 threshold can be correlated to various $C P T$ parameters. 


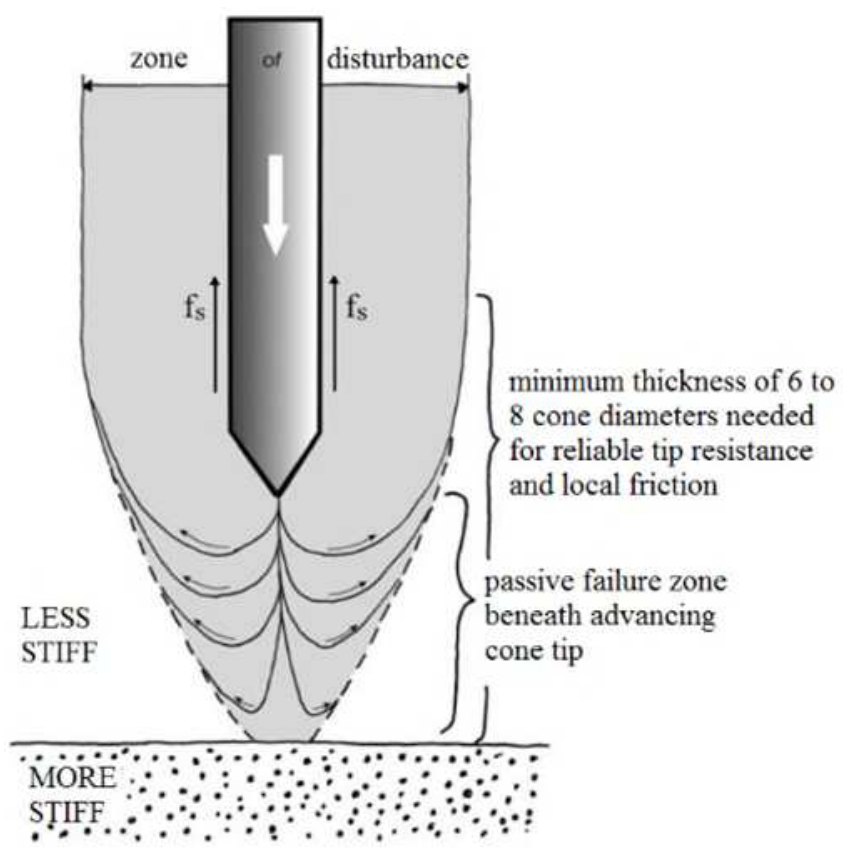

249 Figure 3. Failure mechanism around the base of penetrometer (After Eslami and Mohammadi 2016)

\section{4.2. Prediction of model parameters from CPT data}

252 With regard to Table $\mathbf{3}$, it is clear that $\beta$ and $\gamma$ are roughly constant and equal to approximately 253166.4 and 2.66, respectively. However, $\alpha$ possesses different values. Hence, $\alpha$ in $\boldsymbol{E q}$. (9) can be 254 rewritten as $\boldsymbol{E q}$. (14) with the objective of reaching a general correlation for the hyperbolic 255 model parameter(s).

$256 \alpha=h\left(q_{t}, R_{f}\right)$

257 To date, various approaches have been adopted to derive a general correlation for $\alpha$. The aim in 258 this study is to find a viable formulation, which correlates the model parameters in hyperbolic 259 load-displacement model to the $C P T$ data available in the proximity of the PLT location. To this 260 end, the Volterra series is employed, the implication of which is on the basis of GMDH-type 261 neural network (MolaAbasi et al. 2013; MolaAbasi and Shooshpasha 2017). Instead, the core 262 concept of this regression scheme is to invoke genetic algorithm in combination with the multi- 
263 layer perceptron numeral networks to find an optimized configuration of hidden layers and

264 neurons to form the polynomial correlation. Herein, the Volterra series is rewritten for the two

265 input variables, including $q_{t}$ and $R_{f}$, and a single output, $\alpha$, as $\boldsymbol{E q}$. (15):

$266 \alpha=h\left(q_{t}, R_{f}\right)=a_{1}+a_{2} R_{f}+a_{3} q_{t}+a_{4} R_{f}^{2}+a_{5} q_{t}^{2}+a_{6} q_{t} R_{f}$

267 where the parameters $a_{i}$ are constant variables which are obtained from the regression analysis.

268 To fairly evaluate the efficacy of the proposed model and to compare it with the previous

269 relationships, data were randomly categorized in two groups of training and validation, $70 \%$ of

270 which were used for training and the rest were kept for validation. Therefore, 14 out of the total

27146 data sets, obtained from the $q-s$ curves, were randomly selected for validation data and the

272 rest were utilized for the sake of training. In order to equate the ranges of training and validation

273 in the modeling, their statistical parameters, including minimum, maximum and average, were

274 monitored to remain comparable (MolaAbasi et al. 2015; MolaAbasi and Eslami 2018), as

275 enlisted in Table 4. It is evident that, the statistical characteristics are in a similar level and are

276 quite close to each other.

Table 4. Statistical parameters of the training and validation series.

\begin{tabular}{|c|c|c|c|c|c|c|}
\hline Series & Parameter & $\mathbf{q}_{\mathbf{t}}(\mathbf{k P a})$ & $\mathbf{R}_{\mathbf{f}}$ & $\mathbf{B}(\mathbf{m})$ & $\mathbf{q}(\mathbf{k P a})$ & $\mathbf{S}(\mathbf{m m})$ \\
\hline \multirow{3}{*}{ Training } & average & 4276 & 0.7 & 1 & 787 & 98 \\
\cline { 2 - 7 } & $\min$ & 480 & 0.44 & 0.4 & 170 & 25 \\
\cline { 2 - 7 } & $\max$ & 10720 & 0.66 & 2.35 & 1740 & 260 \\
\hline \multirow{3}{*}{ Validation } & average & 4599 & 0.73 & 1 & 897 & 115 \\
\cline { 2 - 7 } & $\min$ & 880 & 0.48 & 0.3 & 150 & 47 \\
\cline { 2 - 7 } & $\max$ & 10720 & 0.65 & 2.4 & 1740 & 250 \\
\hline
\end{tabular}


279 Aforementioned regression analysis converts $\boldsymbol{E q}$. (9) to Eqs. (16a) and (16b). It should be noted

280 that these correlations are based only on the training data and the validation data has not been

281 introduced to the regression process.

$282 q=\frac{\alpha \frac{s}{B}}{2.68+161 \frac{S}{B}}$

283

$\alpha(M P a)=292.65-1026.95 R_{f}-0.008 q_{t}+964.37 R_{f}^{2}+8.45 \times 10^{-7} q_{t}^{2}+0.05 q_{t} R_{f}$

284 where $q_{t}$ is the corrected $q_{c}$ and $R_{f}$ is the skin friction. With regard to the proposed roughly 285 simple equation, predicted and measured values can be compared. Cases related to the predicted 286 and measured $q-s$ curves are presented in Figure 4, which clearly proves that $\boldsymbol{E q}$. (16) is a 287 powerful modelling tool, according to the statistical parameters provided in Table 5.

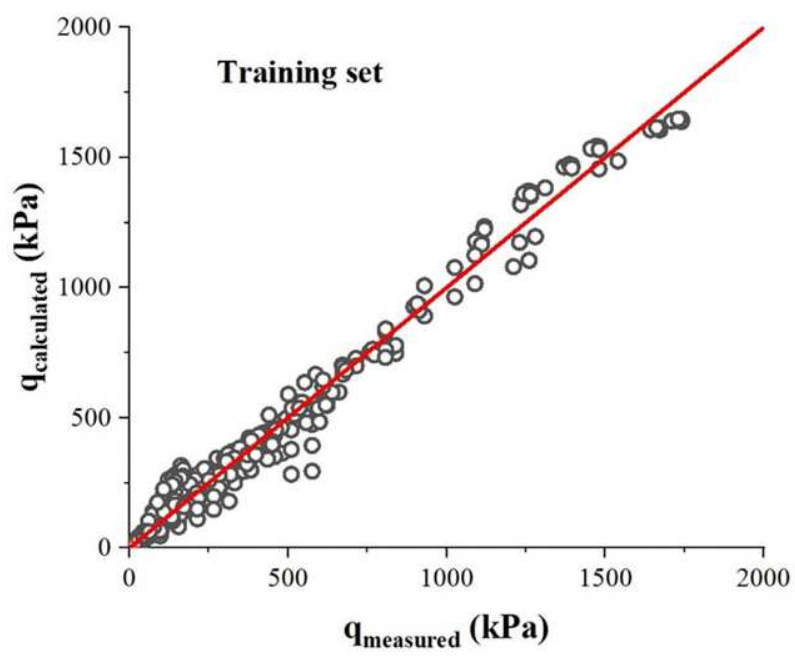

(a)

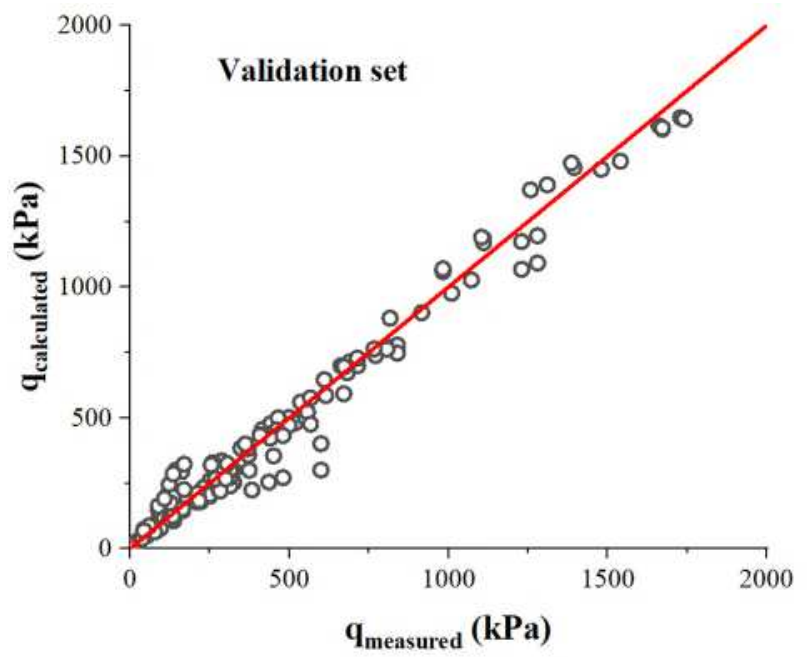

(b)

288 Figure 4. Predicted and measured pressure values for (a) training data set; and (b) validation data set.

Table 5. Statistical results of the model.

\begin{tabular}{|c|c|c|c|}
\hline Model stage & $\mathbf{R}^{\mathbf{2}}$ & $\begin{array}{c}\text { RMSE } \\
(\mathbf{k P a})\end{array}$ & $\begin{array}{c}\text { MAD } \\
(\mathbf{k P a})\end{array}$ \\
\hline Training & 0.992 & 54 & 38 \\
\hline Validation & 0.989 & 64 & 44 \\
\hline Total & 0.990 & 57 & 39 \\
\hline
\end{tabular}




\subsection{Comparison with previous models}

292 Given the very fact that the validation data were not incorporated in the model training process,

293 they are used hereinafter for the purpose of comparison with previous methods to elaborate on

294 the aptitude of different models to imitate the load-displacement trends.

295 To compare the current method with the previous ones, two specific model sets were considered.

296 In the first set, relationships, which predicted $q$-s curves, including those proposed by Mayne

297 and Dasenbrock (2018), Uzielli and Mayne (2011) and Stuedlein and Holtz (2010), were

298 considered and in the second set, correlations proposed by Briaud (2007), Lehane et al. (2013),

299 as well as Robertson (2010) are employed, considering $\frac{S}{B}=0.1$ to assess $q_{u l t}$. In the former set,

300 scaled cumulative frequency $(S C F)$ is presented against the relative error defined in $\boldsymbol{E q}$. (17) for

301 comparison purpose.

$302 \quad E_{r}(\%)=\frac{\mathrm{q}_{c i}-\mathrm{q}_{m i}}{\mathrm{q}_{m i}} \times 100$

303 Figure 5 shows the results of the first set where the relationships suggested by Uzielli and

304 Mayne (2011) and Stuedlein and Holtz (2010) could be observed to render lower values for $q$

305 ( $E_{r}$ is in the negative range). However, Mayne and Dasenbrock (2018) have proposed a more

306 accurate prediction on the basis of the soil type, $I_{c}$. As it is plainly visible, the proposed formula

307 in the current study is way more accurate than the rest as it is much closer to the vertical axis

$308\left(E_{r}=0 \%\right)$ in all ranges of the SCFs and consequently provides a better prediction. On the other

309 hand, positive values of $E_{r}$ indicate that the calculated $q$ is more than its measured value

310 (overestimation); whereas the negative values exhibit an opposite status (underestimation).

311 Previous methods could, at large, be included in the latter group; hence, being more conservative

312 and designs based on these models could be conceived more cost prohibitive. 
313 In the latter set, however, the calculated vs. measured ultimate bearing capacity values have been

314 employed to indicate the accuracy of the proposed relationships. Likewise, statistical parameters,

315 such as $R^{2}, R M S E$, and $M A D$, have been superimposed on the curves to make a quantitative

316 comparison, as depicted in Figure 6. It is evident that, the method presented in the current study

317 poses more aptitude to estimate $q_{u l t}$ in comparison to the other approaches.

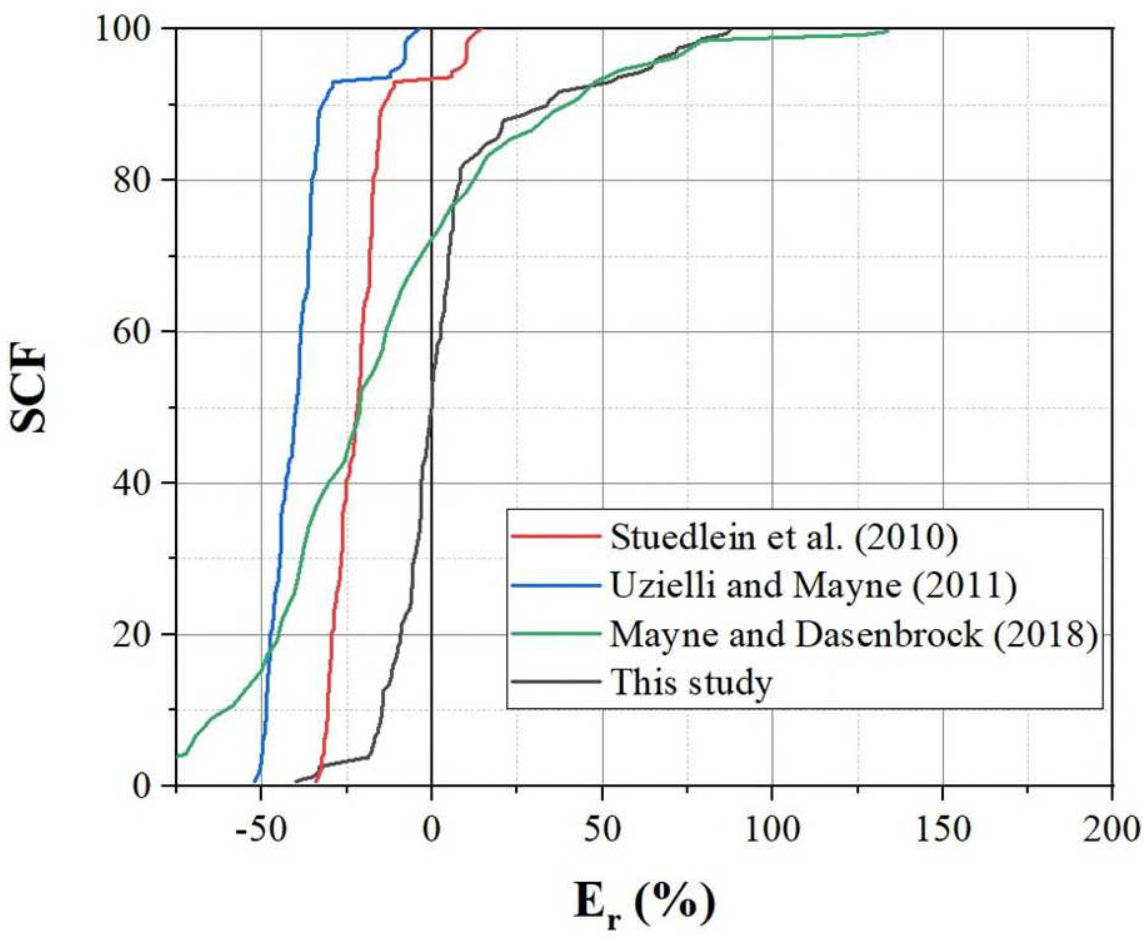

Figure 5. Graphical representation of the accuracy of empirical correlations. 

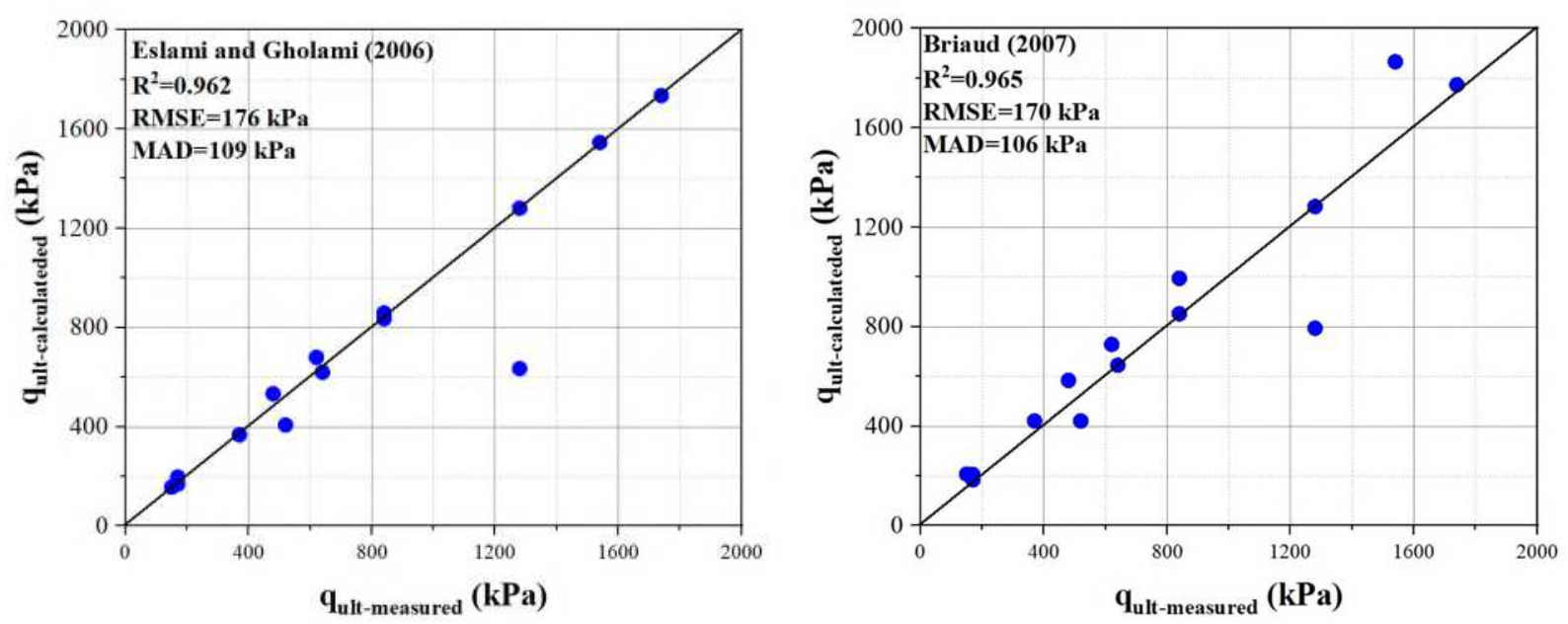

320
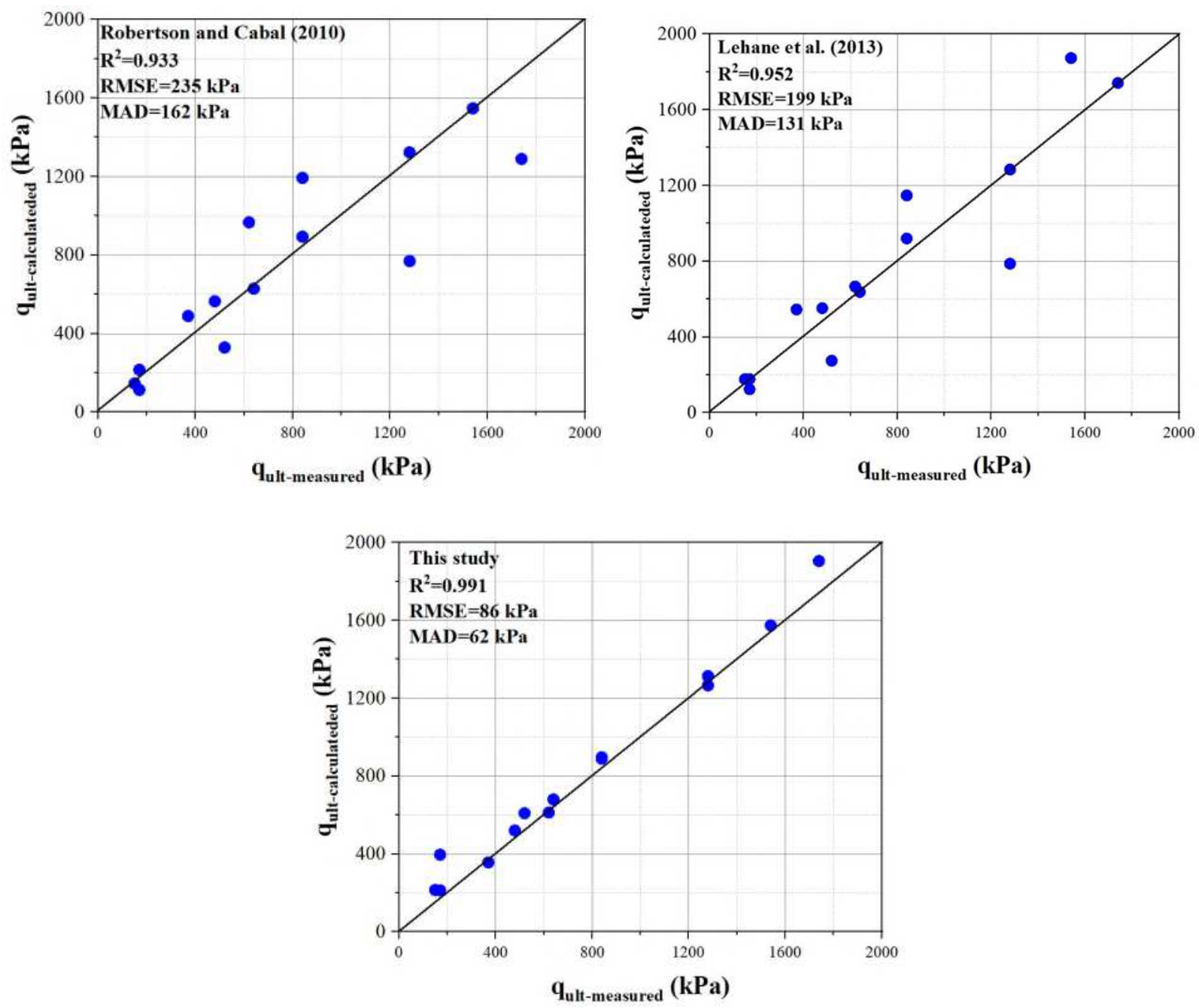

Figure 6. Comparison of the accuracy of the current study in estimation of the ultimate bearing capacity of shallow footings with other relationships proposed in the literature. 


\subsection{Sensitivity analysis}

326 In order to examine the effect of every single input variable on the output parameter, sensitivity

327 analyses were performed by changing each of the input parameters at a constant pace while the

328 rest were unwavering (Liong et al. 2000). The considered rate of changes ranges from $-10 \%$ to

$32910 \%$. As a result of the changes in every input variable, $R M S E$ in the estimation of output $(q)$ was

330 determined and presented in Figure 7. In other words, the sensitivity analysis with respect to the

331 changes of the parameter under study is drawn, while other parameters were adopted in the

332 average sense; that is, changes of RMSE with respect to the input variables. As it is plainly

333 demonstrated, the changes in parameters $B$ and $s$ barely affect $q$; whereas the variations of $R_{f}$ and

$334 q_{t}$, particularly $R_{f}$, have substantial influences on the output parameters. Variations of the left

335 sides of Figure 7 in terms of $R_{f}$ and $q_{t}$ are almost similar whereas changes in the right hand side

336 of $R_{f}$ curve are more pronounced. Such a result corroborates that $R_{f}$ is the most influential

337 parameter on RMSE.

338 Another observation from Figure 7 is that any perturbation in the measured soil parameters $q_{t}$

339 and $R_{f}$, which can be considered as epistemic uncertainty and could be presumably due to

340 measurement error, will have a reflection on the accuracy of the load/pressure estimations for

341 shallow foundations. In other words, one could easily deduce that the soil parameters

342 measurements, substantiated in form of in-situ tests logging, have paramount impacts on the

343 accuracy of the relevant predictions as appears from Figure 7. This would imply that the type of

344 in-situ test equipment and its measurement accuracy play a crucially important part in the

345 appropriate estimation of other parameters, let's say the ultimate bearing capacity of shallow 346 footings for example. 

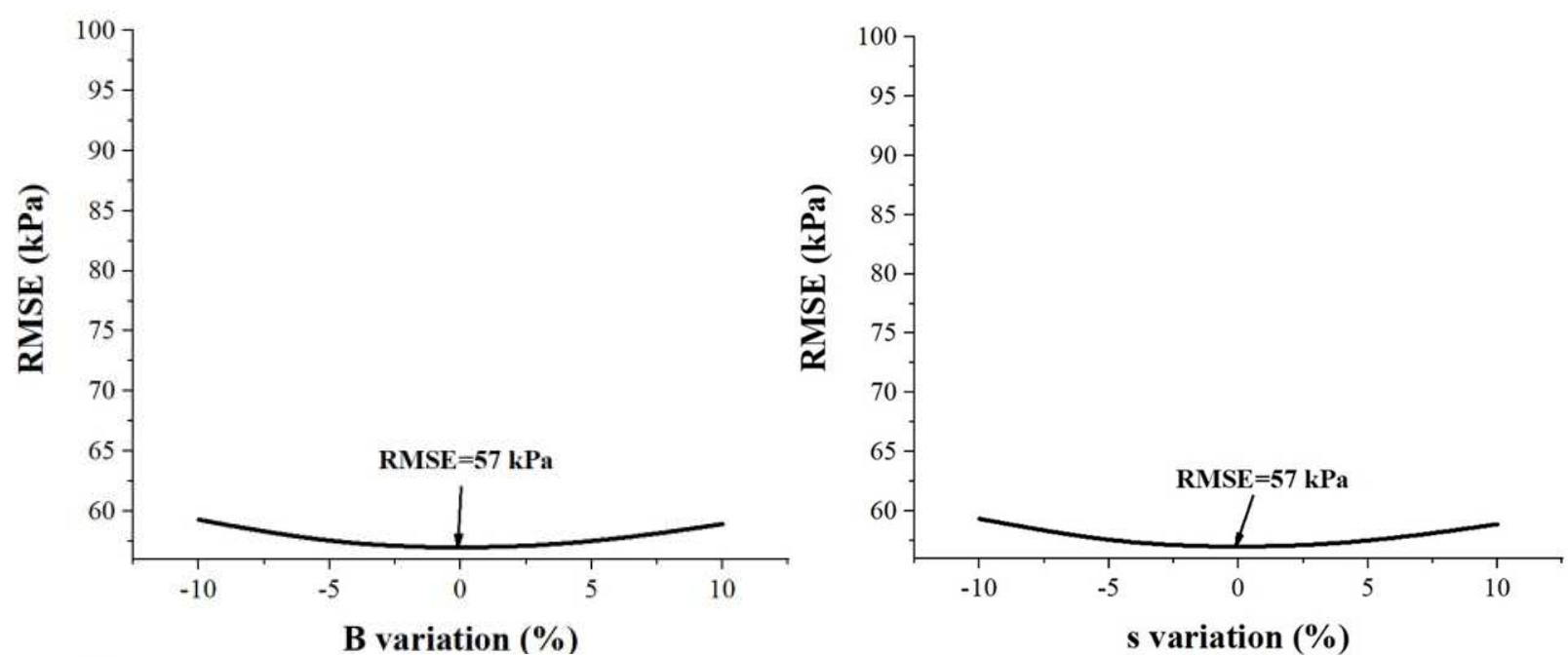

347
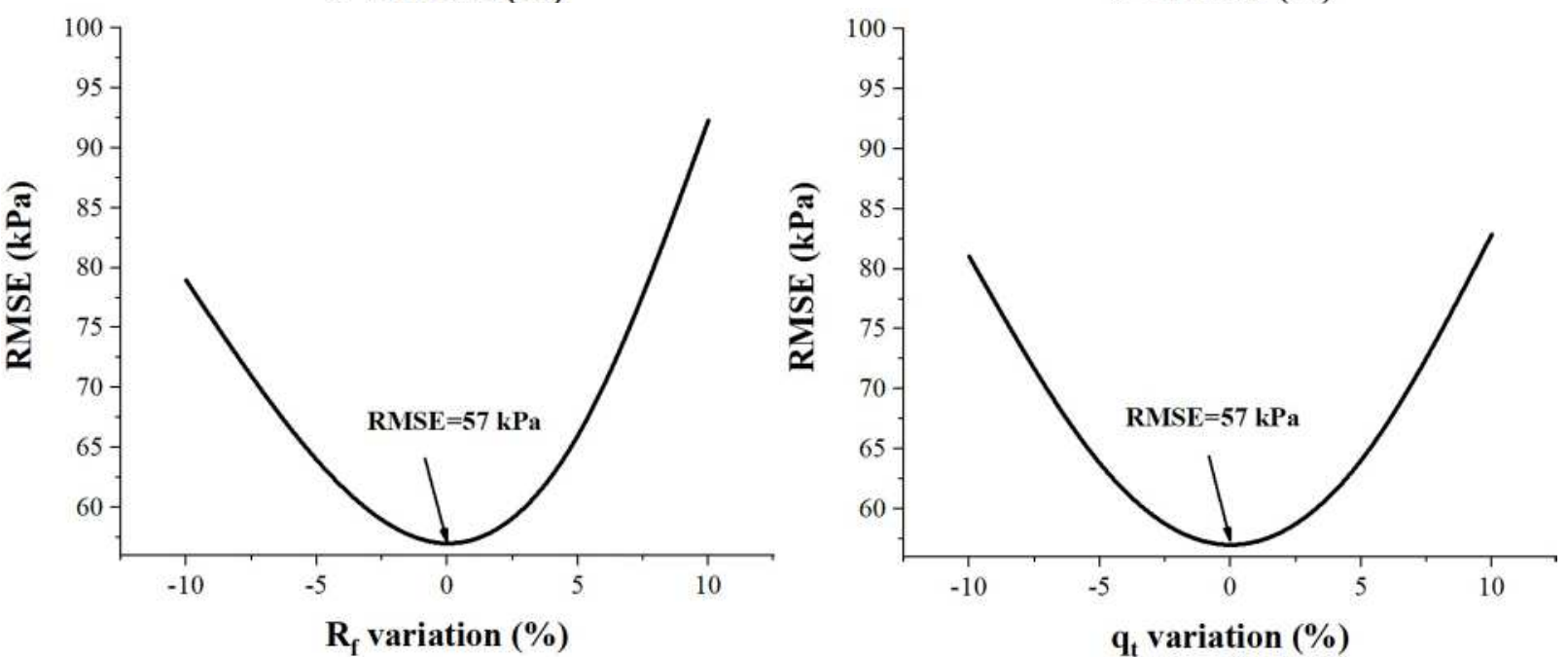

Figure 7. Results of the sensitivity analysis of the input parameters.

\subsection{Application of the proposed model for future cases}

351 The efficiency of the current approach for the new data set related to sands and silty sands and

352 the calculation of the corresponding settlement are presented scematically in Figure 8. First, a

$353 C P T \log$ is considered and then, parameters $q_{t}$ and $R_{f}$ are drawn against the depth (Figure 8a).

354 With regard to the defined $D_{f}$ and $B, C P T$ data series are derived from $D_{f}$ to $D_{f}+2 \mathrm{~B}$ and their

355 average values are taken into account (Figure 8b). The arithmetic mean values of the parameters

$356 q_{t}$ and $q_{c}$, obtained from $C P T$ data are considered in the current study. Using this arithmetic

357 mean, resistance peaks are filtered using the method presented by Eslami and Fellenius (1997). 
358 Finally, by introducing the mean values of $q_{t}$ and $R_{f}$, acquired from the $C P T \log , \alpha$ presented in $359 \boldsymbol{E} \boldsymbol{q} .(\mathbf{1 6 b})$ is computed. Thereafter, the values of the applied pressures corresponding to various 360 settlement levels could be obtained from Eq. (16a) and the graph presented in Figure 8c could 361 be drawn accordingly. To this end, six values for the settlement ( $s_{1}$ to $s_{6}$ ) are considered 362 schematically and the respective values of the applied pressure ( $q_{1}$ to $\left.q_{6}\right)$ are acquired so as to 363 draw a complete load-settlement profile.
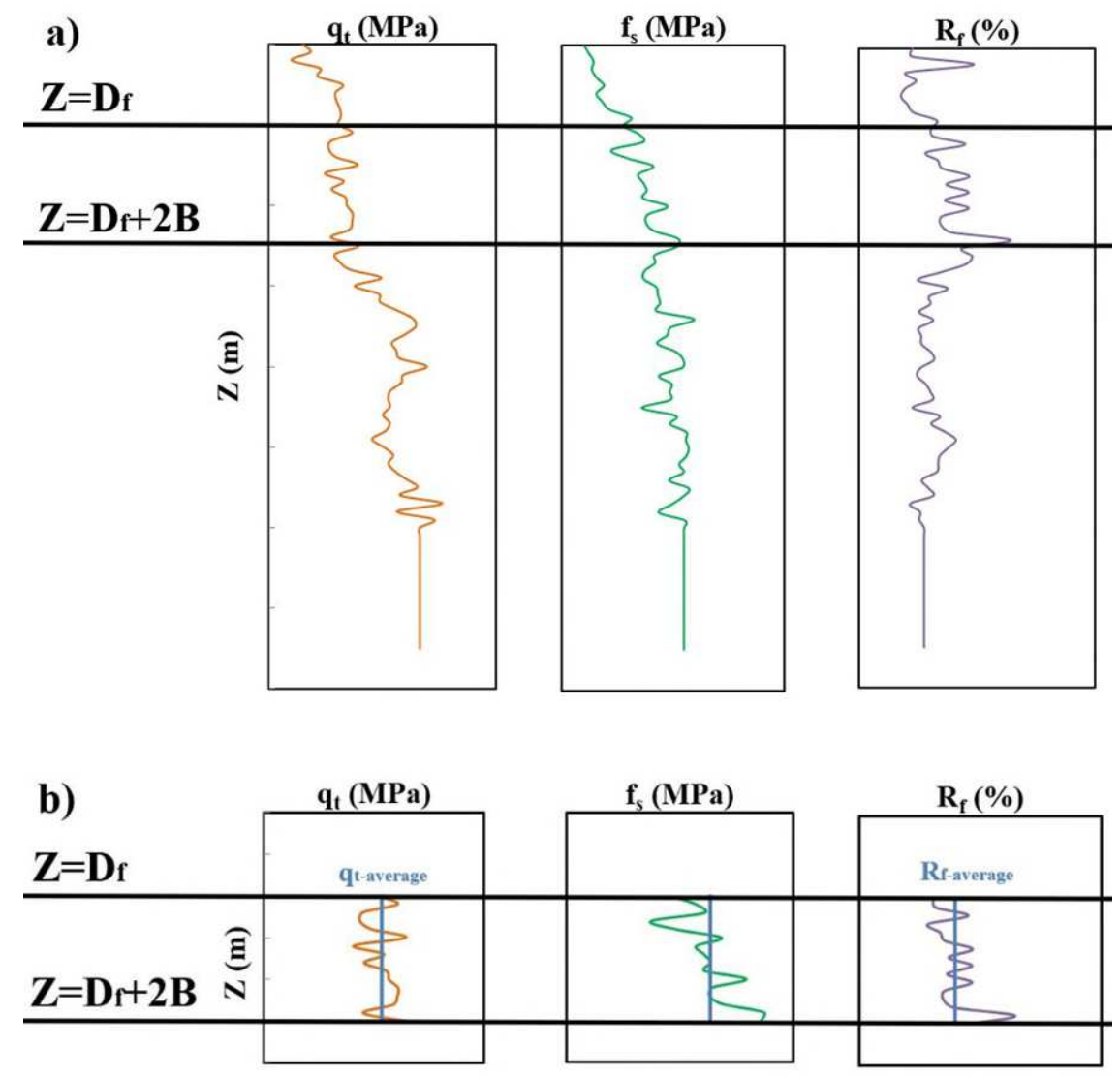


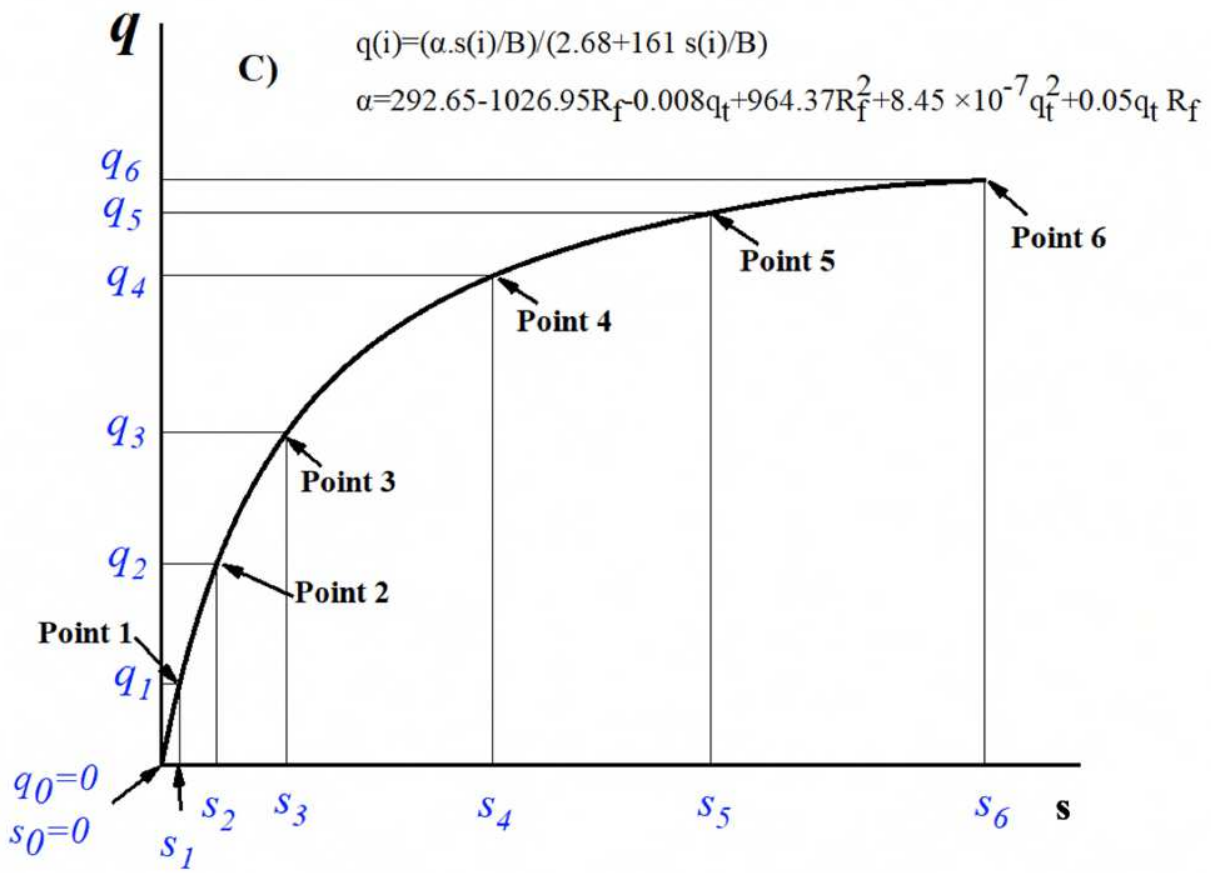

Figure 8. Schematic illustration of the load-settlement curves based on $C P T$ results.

\section{DISCUSSION}

369 The main purpose of the current study was to find a robust relationship for the load-settlement

370 behavior of soils based on CPT results. Such end was obtained in accordance with the gathered

371 in-situ test results. The proposed formula is $\boldsymbol{E q}$. (16), which correlates $q$ to $s, B$ and other

372 properties obtained from $C P T$ data components, such as $R_{f}$ and $q_{t}$. The results show the 373 superiority of the proposed relationship over previous ones.

\section{5.1. Ultimate bearing capacity $\left(q_{u l t}\right)$}

375 Based on different criteria for $q_{u l t}$ obtained from $P L T$ s, loading up to $0.1 B$ settlement is valid 376 particularly for coarse-grained soils and sands. Hence, applying this criterion and putting it into $377 \boldsymbol{E q}$. (16), Eq. (18) can be proposed for the evaluation of the ultimate bearing capacity based on $C P T$ results. 
where $q_{t}$ is the corrected $q_{c}$ in $k P a$ and $R_{f}$ is the skin friction in percent. A $3 D$ illustration of the 381 variation of $q_{u l t}$ with respect to $q_{t}$ and $R_{f}$ is given in Figure 9. As depicted, the increase in either 382 CPT parameters leads to an increase in the ultimate bearing capacity. However, the rate of 383 increase in the $q_{u l t}$ value with the increase of $q_{t}$ is more than that of $R_{f}$. Moreover, for higher 384 values of tip resistance, $R_{f}$ is observed to be more influential. This phenomenon shows that the cohesive property will be enhanced in soils due to the increase of $R_{f}$, which consequently gives rise to the augmentation in the ultimate bearing capacity.

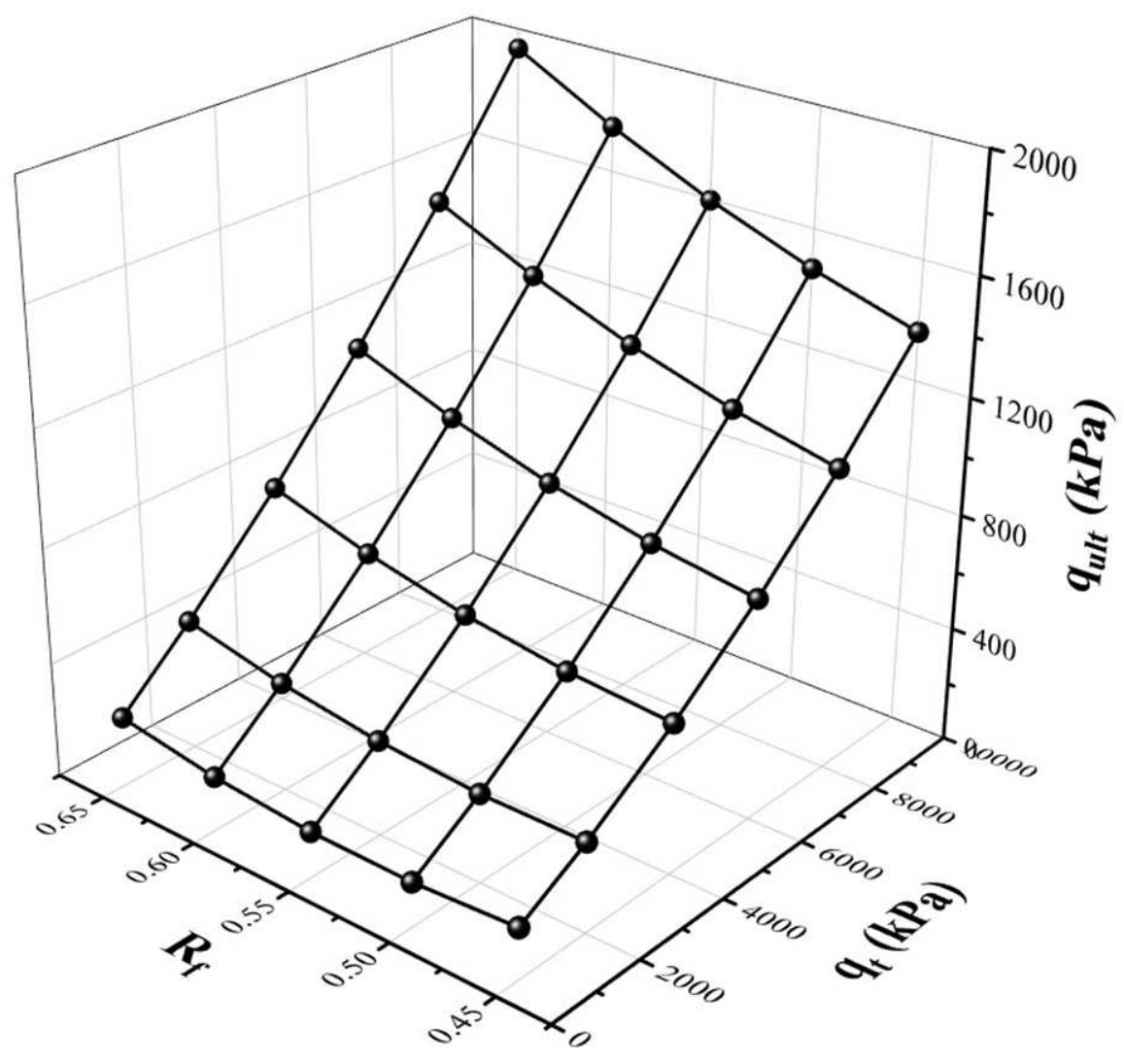

Figure 9. Ultimate bearing capacity curve based on CPT data.

Based on the results of a PLT, the settlement corresponding to the failure of the plate can be obtained. In order to link the settlement values of a PLT to a true scale foundation, Eq. (19) can 
391 be adopted from Terzaghi et al. (1996), which relates the settlement of the foundation $\left(s_{f}\right)$ to the

392 settlement of the plate $\left(s_{p}\right)$.

393

$$
\begin{cases}s_{f}=s_{p} \frac{B_{f}}{B_{p}} & \text { clayey soil } \\ s_{f}=s_{p}\left\{\frac{\left[B_{f}\left(B_{p}+0.3\right)\right]}{\left[B_{p}\left(B_{f}+0.3\right]\right.}\right\}^{2} & \text { sandy soil }\end{cases}
$$

394 where $B_{f}$ and $B_{p}$ are the width (diameter) of the foundation and plate, respectively.

395 Accordingly, the ultimate bearing capacity of the foundation $\left(q_{u l t, f}\right)$ and plate $\left(q_{u l t, p}\right)$ can be 396 related as follows:

397

$$
\begin{cases}q_{u l t, f}=q_{u l t, p} & \text { clayey soil } \\ q_{u l t, f}=q_{u l t, p}\left(\frac{B_{f}}{B_{p}}\right) & \text { sandy soil }\end{cases}
$$

398 Based on the above-mentioned discussion, the factor of safety can be reached as follows:

399 1. Calculating the allowable settlement of the plate $\left(s_{p, a l l}\right)$ based on the values of $B_{f}, B_{p}$ and $400 s_{f, \text { all }}$, using the relations provided in foundation manuals for the relevant soil type.

401 2. Based on the value of $\mathrm{q}_{\mathrm{t}}$ from the $C P T$ data (i.e., the average $q_{t}$ values corresponding to the depths of $D_{f}$ to $D_{f}+2 B$ ) and the value of $s_{p}$, all, the value of $q_{a}$ for the plate can be obtained.

3. Obtaining $q_{u l t}$ based on the criterion of $\frac{s}{B}=0.1(\boldsymbol{E q} .18)$ and calculating the factor of safety

\subsection{Load-settlement curve (q-s)}

406 One of the applications of $\boldsymbol{E q}$. (16) is to delineate the q-s profile, while representing the load407 displacement behavior of the footing, as depicted in a three-dimensional fashion in Figure $\mathbf{1 0}$ for $408 B=1 \mathrm{~m}$. From the graphs, it could be observed that $q$-s surfaces grow with $R_{f}$, implying higher $q$ 409 values in similar settlement levels. On the other hand, for the predetermined settlements of 50 
410 and $100 \mathrm{~mm}, q_{a}$ can be drawn in the $q-q_{t}$ plane, as also shown in Figure 10. As it can be seen,

411 the values of $q_{a}$ corresponding to $100 \mathrm{~mm}$ settlement are detectably higher than those 412 corresponding to $50 \mathrm{~mm}$ settlement with both increasing with $R_{f}$ value.
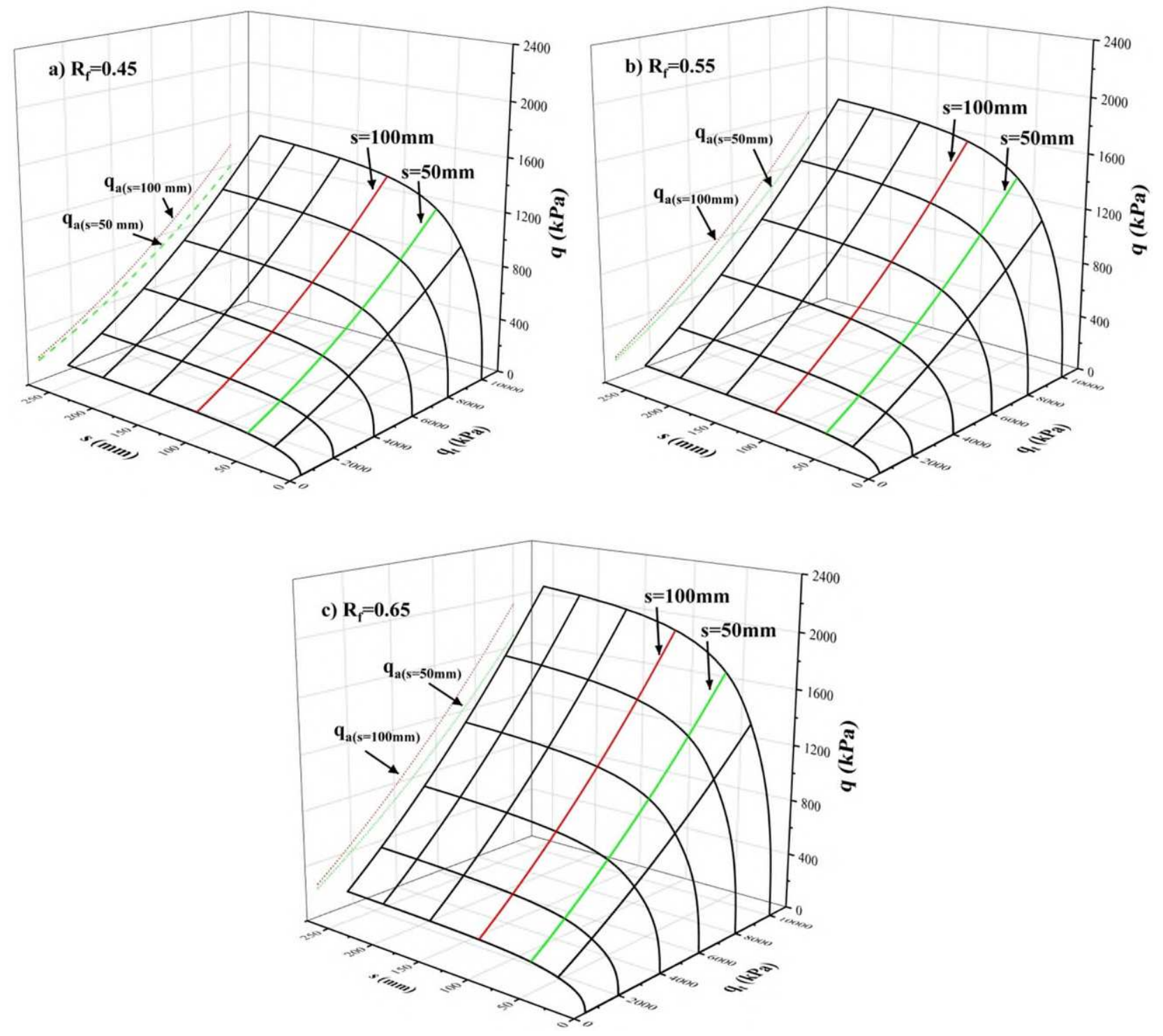

Figure 10. Variations of $q$ against settlement and $C P T$ parameters for $B=1 \mathrm{~m}$.

\section{5.3. Modulus of subgrade reaction $\left(\boldsymbol{k}_{s}\right)$}

415 Another application of Eq. (16) is to predict the modulus of subgrade reaction $\left(k_{s}\right)$. As stated 416 before (Figure 1), $k_{s}$ can be predicted from the $q$-s curve acquired from PLT data and can be 
417 computed for foundations employing $\boldsymbol{E q}$. (9). Figure 11 shows the three-dimensional 418 representation of $k_{s}$ as a function of $q_{t}$ and $s$ for the case of $B=1 \mathrm{~m}$. It should be noted that the 419 considered value of $R_{f}$ for this graph is the average of all data; i.e. $R_{f}=0.6$. As it is clear from the 420 figure, settlement is inversely related to the modulus of subgrade reaction, whereas $q_{t}$, as an 421 indicative of soil strength properties, has an augmenting influence on $k_{s}$. Generally, settlement is 422 more of consequence than $q_{t}$.

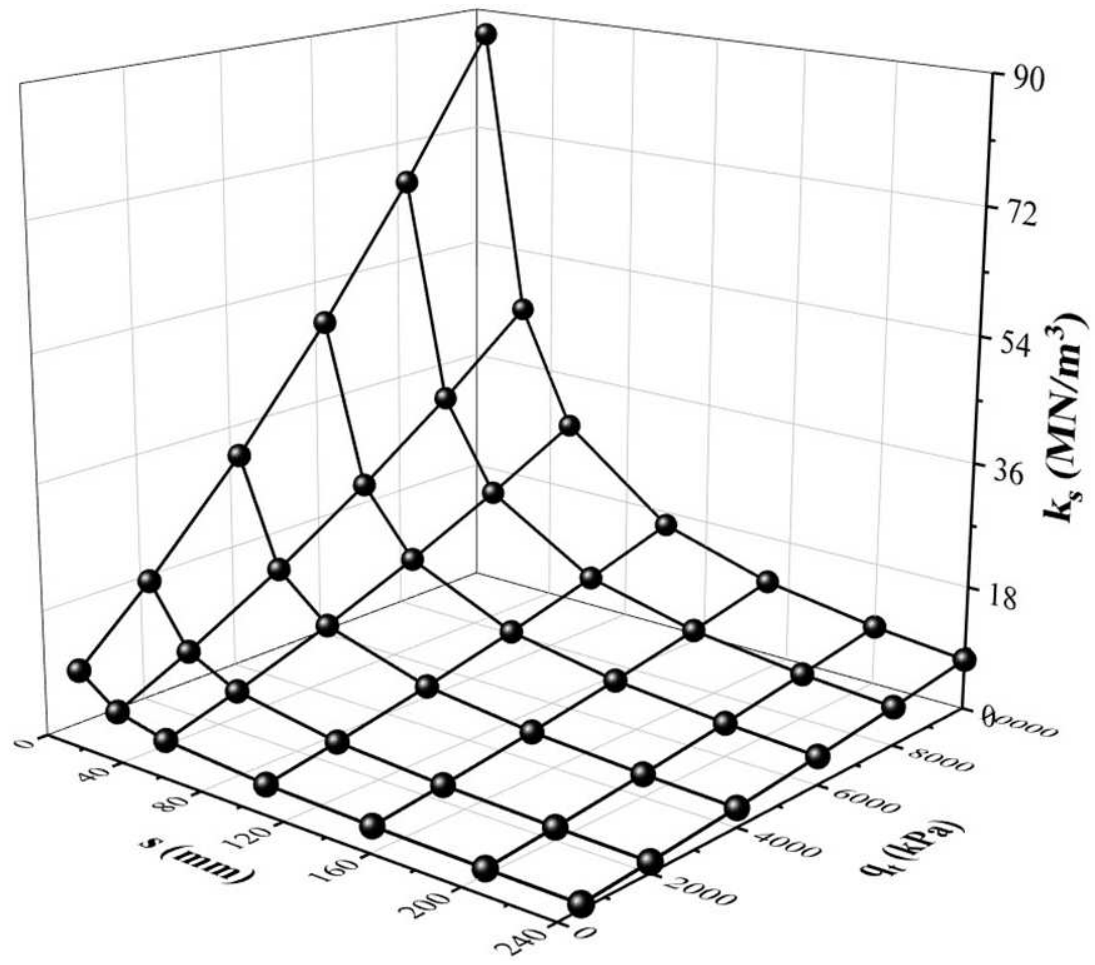

424 Figure 11. Variation of the modulus of subgrade reaction against $q_{t}$ with respect to different settlement levels $\left(R_{f}=0.6\right)$.

\section{CONCLUSIONS}

427 In the current paper, a general framework was developed to predict and model the load428 settlement response of shallow foundations based on $C P T$ results. To this end, $46 q-s$ curves 429 were carefully assessed and a sensitivity analysis was also conducted. Moreover, the proposed 
430 model was compared to previous relationships readily available from literature. Prominent

431 results obtained in the course of this study include:

432 - The proposed hyperbolic function was proven to have a high accuracy to predict the load433 settlement behavior of shallow foundations.

$434 \quad-\quad$ Constant parameters of the current hyperbolic model, including $\gamma$ and $\beta$, stem from the 435 general form of the $q-s$ curves and the variable coefficient, $\alpha$, is dependent on the soil 436 strength properties obtained from $C P T$ results. $\alpha$ was related to the corrected cone tip 437 resistance $\left(q_{t}\right)$ and skin friction $\left(R_{f}\right)$ via regression analysis and the Volterra series.

438 - Dimensionless parameter $\frac{S}{B}$ was used and simple equations with high accuracy were 439 proposed to estimate the allowable and ultimate bearing capacities of shallow 440 foundations.

441 - To have a more accurate investigation, data were categorized into two groups of training 442 and validation and the model parameters were estimated. Validation data were employed 443 to make a comparison between the proposed model and previous ones, the results of 444 which showed considerably high accuracy of the developed model $\left(R^{2}>99 \%\right)$.

445 - Sensitivity analysis was performed to assess the individual impacts of the input variables, 446 the results of which demonstrated the higher sensitivity of the model output to $R_{f}$.

$447 \quad$ - All the results of $q_{\max }, q_{u l t}, q_{a}$ and $k_{s}$ were given in the forms of example $3 D$ graphs to be $448 \quad$ readily used by potential readers.

\section{Compliance with ethical standards}

451 Funding: No funding was received for conducting this study.

452 Conflicts of Interest: The authors declare no conflict of interest. 
453 Ethical approval: This article does not contain any studies with human participants performed

454 by any of the authors.

455 Informed consent: Participants of the study were the authors and informed consent is not valid.

\section{REFERENCE}

459 Ahmed, S.I., and Siddiqua, S. 2016. Compressibility behavior of soils: a statistical approach.

Al-Shamrani, M.A. 2005. Applying the hyperbolic method and C /Cc concept for settlement prediction of Geotechnical and Geological Engineering, 34(6): 2063-2070. Springer. complex organic-rich soil formations. Engineering geology, 77(1-2): 17-34. Elsevier.

Amar, S., Baguelin, F., Canepa, Y., and Frank, R. 1998. New design rules for the bearing capacity of shallow foundations based on Ménard pressuremeter tests. In Geotechnical site characterization. pp. 727-733.

466 Bowles, L.E. 1996. Foundation analysis and design. McGraw-hill.

467 Briaud, J.-L. 2007. Spread footings in sand: load settlement curve approach. Journal of Geotechnical and Geoenvironmental Engineering, 133(8): 905-920. American Society of Civil Engineers.

Briaud, J.-L., and Gibbens, R. 1999. Behavior of five large spread footings in sand. Journal of Geotechnical and Geoenvironmental Engineering, 125(9): 787-796. American Society of Civil Engineers.

Decourt, L. 1999. Behavior of foundations under working load conditions. 11th Pan-American Conferenvce on Soil Mechanics and Geotechnical Engineering, Foz do Iguaçu, 4: 453-488.

Eslami, A., Alimirzaei, M., Aflaki, E., and Molaabasi, H. 2017. Deltaic soil behavior classification using CPTu records-Proposed approach and applied to fifty-four case histories. Marine Georesources \& Geotechnology, 35(1): 62-79. Taylor \& Francis.

Eslami, A., and Fellenius, B.H. 1997. Pile capacity by direct CPT and CPTu methods applied to 102 case histories. Canadian Geotechnical Journal, 34(6): 886-904. NRC Research Press Ottawa, Canada.

Eslami, A., and Mohammadi, A. 2016. Drained soil shear strength parameters from CPTu data for marine deposits by analytical model. Ships and Offshore Structures, 11(8): 913-925. Taylor \& Francis. (CPTu and CPT) Applications in Foundation Engineering. Butterworth-Heinemann. 
Eslami, A. and Gholami, M. 2006. Analytical Model for the Ultimate Bearing Capacity of Foundations from Cone Resistance. Scientia Iranica, 13(3), pp.223-233.

Farouk, H., and Farouk, M. 2014. Calculation of subgrade reaction modulus considering the footing-soil system rigidity. In Vulnerability, Uncertainty, and Risk: Quantification, Mitigation, and Management. pp. 2498-2507.

Fellenius, B.H. 2015. Static tests on instrumented piles affected by residual load. DFI Journal-The Journal of the Deep Foundations Institute, 9(1): 11-20. Taylor \& Francis.

Fellenius, B.M., and Altaee, A. 1994. Stress and settlement of footings in sand. GEOTECHNICAL SPECIAL PUBLICATION,: 1760. Citeseer.

Holtz, R.D., Kovacs, W.D., and Sheahan, T.C. 2011. An introduction to geotechnical engineering. Pearson Upper Saddle River, NJ.

Kulhawy, F.H. 2004. On the axial behavior of drilled foundations. In GeoSupport 2004: drilled shafts, micropiling, deep mixing, remedial methods, and specialty foundation systems. pp. 34-51.

Lehane, B.M. 2012. Relating foundation capacity in sands to CPT qc. Geotechnical and Geophysical Site Characterization 4,: 63. CRC Press.

Lehane, B.M., Li, Y., and Williams, R. 2013. Shaft capacity of displacement piles in clay using the cone penetration test. Journal of Geotechnical and Geoenvironmental Engineering, 139(2): 253-266. American Society of Civil Engineers.

Liong, S.-Y., Lim, W.-H., and Paudyal, G.N. 2000. River stage forecasting in Bangladesh: neural network approach. Journal of computing in civil engineering, 14(1): 1-8. American Society of Civil Engineers.

Liu, Y., and Zheng, Y. 2019. Plastic Mechanics of Geomaterial. Springer.

Mayne, P.W. 2014. Interpretation of geotechnical parameters from seismic piezocone tests. In Proceedings, 3rd International Symposium on Cone Penetration Testing. pp. 47-73.

Mayne, P.W., and Dasenbrock, D. 2018. Direct CPT Method for 130 Footings on Sands. In Innovations in Geotechnical Engineering. pp. 135-146.

Mayne, P.W., and Illingworth, F. 2010. Direct CPT method for footing response in sands using a database approach. In Proceedings of the 2nd International Symposium on Cone Penetration Testing., Huntington Beach, Calif.

Mayne, P.W., Uzielli, M., and Illingworth, F. 2012. Shallow footing response on sands using a direct method based on cone penetration tests. In Full-Scale Testing and Foundation Design: Honoring Bengt H. Fellenius. pp. 664-679. 
Mohseni, S., Payan, M., and Jamshidi Chenari, R. 2018. Soil-structure interaction analysis in natural heterogeneous deposits using random field theory. Innovative Infrastructure Solutions, 3(1): 62. Springer.

MolaAbasi, H., Dikmen, U., and Shooshpasha, I. 2015. Prediction of shear-wave velocity from CPT data at Eskisehir (Turkey), using a polynomial model. Near Surface Geophysics, 13(2): 155-167.

MolaAbasi, H., and Eslami, A. 2018. Prediction of drained soil shear strength parameters of marine deposit from CPTu data using GMDH-type neural network. Marine Georesources \& Geotechnology,: 1-10. Taylor \& Francis. doi:10.1080/1064119X.2017.1415400.

MolaAbasi, H., Eslami, A., and Shourijeh, P.T. 2013. Shear wave velocity by polynomial neural networks and genetic algorithms based on geotechnical soil properties. Arabian Journal for Science and Engineering, 38(4): 829-838. Springer.

MolaAbasi, H., and Shooshpasha, I. 2017. Polynomial Models Controlling Strength of Zeolite-Cement Sand Mixtures. Scientia Iranica, 24(2): 526.

Naeini, S.A., Moayed, R.Z., Kordnaeij, A., and Mola-Abasi, H. 2018. Prediction of subgrade reaction modulus of clayey soils using group method of data handling. Scientia Iranica,. Sharif University of Technology.

Robertson, P.K. 2010. Soil behaviour type from the CPT: an update. In 2nd International symposium on cone penetration testing. pp. 575-583.

Robertson, P.K. and Cabal, K.L. 2014. Guide to cone penetration testing. Sixth edition. Published by Gregg In-situ, Signal Hill, California: 126 pages.

Saftner, D., and Dagger, R. 2018. Cone Penetration Testing Manual for Highway Geotechnical Engineers.

Schmertmann, J.H. 1978. Guidelines for cone penetration test: performance and design. United States. Federal Highway Administration.

Soltani, A., Deng, A., Taheri, A., Sridharan, A., and Estabragh, A.R. 2017. A framework for interpretation of the compressibility behavior of soils. Geotechnical Testing Journal, 41(1): 1-16. ASTM International.

Sridharan, S. 2006. Non-vanishing derivatives of Lyapunov exponents and the pressure function. Dynamical Systems, 21(4): 491-500. Taylor \& Francis.

Stuedlein, A.W., and Holtz, R.D. 2010. Undrained displacement behavior of spread footings in clay. In Art of Foundation Engineering Practice. pp. 653-669.

Terzaghi, K. 1955. Evalution of conefficients of subgrade reaction. Geotechnique, 5(4): 297-326. Thomas Telford Ltd. 
547 Terzaghi, K., Peck, R.B., and Mesri, G. 1996. Soil mechanics in engineering practice. John Wiley \& $548 \quad$ Sons.

549 Uzielli, M., and Mayne, P.W. 2011. Serviceability limit state CPT-based design for vertically loaded 550 shallow footings on sand. Geomechanics and Geoengineering: An international journal, 6(2): 91551 107. Taylor \& Francis.

552 Valikhah, F., and Eslami, A. 2019. CPT-Based Nonlinear Stress-Strain Approach for Evaluating 553 Foundation Settlement: Analytical and Numerical Analysis. Arabian Journal for Science and $554 \quad$ Engineering, 44(10): 8819-8834. Springer.

555 Vesic, A.B. 1961. Beams on elastic subgrade and the Winkler's hypothesis. In Proc. 5th Int. Conf. on 556 SMFE. pp. 845-851.

557 Vesic, A.S. 1975. Bearing Capacity of Shallow Foundations, Foundation Engineering Handbook, ed. $558 \quad$ Winterkorn, FS and Fand, HY. Van Nostrand Reinhold, New York.

559 Zhang, Q.Q., Li, S.C., Liang, F.Y., Yang, M., and Zhang, Q. 2014. Simplified method for settlement 560 prediction of single pile and pile group using a hyperbolic model. International Journal of Civil $561 \quad$ Engineering, 12(2): 146-159. International Journal of Civil Engineering. 